\title{
Testing for contagion in international financial markets: which way to go?
}

\author{
Sébastien Wälti
}

Graduate Institute of International Studies

\begin{abstract}
This paper tests for the existence of contagion during the 1997/98 Asian crisis. We interpret contagion as a significant change in the way that country-specific shocks are transmitted across international financial markets. Using the full-information framework of Favero and Giavazzi (2002) we find that the null hypothesis of no contagion is widely rejected. We also uncover evidence of an asymmetric transmission of shocks. Since our results contrast with those obtained by Rigobon $(2001,2002)$ using a limited-information methodology we present Monte Carlo simulations which show that certain necessary conditions must be satisfied for this method to have power. For parameter values in line with our econometric estimations we conclude that the power of the limited-information approach remains relatively low.
\end{abstract}

(C) The Authors.

All rights reserved. No part of this paper may be reproduced without the permission of the authors. 


\title{
Testing for contagion in international financial markets: which way to go?
}

\author{
Sébastien Wälti* \\ First version: December 2002 \\ This version: August 2003
}

\begin{abstract}
This paper tests for the existence of contagion during the 1997/98 Asian crisis. We interpret contagion as a significant change in the way that countryspecific shocks are transmitted across international stock markets. Using the full-information framework of Favero and Giavazzi (2002) we find that the null hypothesis of no contagion is widely rejected. We also uncover evidence of an asymmetric transmission of shocks. Since our results contrast with those obtained by Rigobon (2001, 2002) using a limited-information methodology we present Monte Carlo simulations which show that certain necessary conditions must be satisfied for this method to have power. For parameter values in line with our econometric estimations we conclude that the power of the limitedinformation approach remains relatively low.
\end{abstract}

JEL Classification: C3, F3, F4, G1

Keywords: Contagion, nonlinearities, international financial markets, Asian crisis, simultaneous equation models.

${ }^{*}$ Graduate Institute of International Studies, Pavillon Rigot, Avenue de la Paix 11a, CH-1202 Geneva, Switzerland. Email: walti8@hei.unige.ch. I am grateful to Hans Genberg and Charles Wyplosz for insightful comments and suggestions. Financial support from the International Center for Financial Asset Management and Engineering (FAME) is gratefully acknowledged. All remaining errors are mine. 


\section{Executive summary}

During the last decade international financial markets have been affected by several major currency and financial crises. Although such episodes of turbulence are not a new phenomenon, the apparent high degree of international transmission of these crises has triggered a large research effort both at the theoretical and empirical levels. The keyword is contagion.

The existing empirical literature focuses on two related sets of issues. On the one hand, a large number of studies aims to distinguish through which channels countryspecific shocks such as sharp devaluations or banking crises are propagated across nations. The goal is to discriminate between different explanations for this propagation: trade linkages, financial integration, macroeconomic similarities, common lender effects, common external disturbances, etc. On the other hand, the second set of issues deals with the existence of contagion defined in a particular way. In this branch of the literature, contagion is defined as a significant change in the way that country-specific shocks are transmitted internationally. In other words, we can specify a null hypothesis that the underlying transmission mechanism is stable across tranquil periods and episodes of high financial turbulence. While the first set of issues deals with the nature of interdependence, the second set focuses on how interdependence is affected by abnormal high-volatility events in financial markets.

In fact, simply testing whether shocks are transmitted across borders does not make much sense. The process of globalization has reinforced the various linkages between open economies, thereby making these more interdependent. To this extent, observing transmission of economic disturbances should come as no surprise. A more interesting question is whether the strength of the transmission mechanism remains stable over time. This is the central question of the contagion literature and it is this question that lies at the core of this paper.

The traditional empirical approach makes use of correlation analysis. The central idea is to assess whether the correlation coefficient between two stock markets changes across periods of low and high volatility. However, numerous studies have recognized that focusing on correlations can be misleading. Moreover, such an approach does not properly model the interdependence across international financial markets. Therefore, recent research builds upon structural models of simultaneous equations which aim is to properly account for interdependencies. Rigobon (2001, 2002) proposes a limited-information procedure which uses the heteroscedastic feature of highfrequency financial data to build an instrumental variable. In this context, a test for contagion amounts to testing for the validity of the constructed instrument. When this methodology is applied to emerging markets it is found that the transmission mechanism remains stable over time. In other words, contagion does not exist.

Our paper pursues two objectives. Firstly, we use an alternative empirical approach pioneered by Favero and Giavazzi (2002) and test for the existence of contagion during the 1997/98 south-east Asian crisis. We focus on five countries, namely the Philippines, Korea, Malaysia, Thailand and Indonesia. In contrast with Rigobon 
(2002) we uncover strong evidence against the null hypothesis of a stable transmission mechanism. In other words, contagion exists and country-specific shocks are propagated internationally in a nonlinear way. Interestingly, positive shocks can have either a positive or a negative impact on other stock markets, whereas negative shocks have a more systematic negative effect on other markets. We interpret this result as prima facie evidence that investors discriminate among stock markets in good times, but tend to exit all markets in bad times.

Secondly, to the extent that the empirical results on the existence of contagion depend upon the chosen methodology, we study possible methodological explanations for this divergence using Monte Carlo simulations. We study the power of the approach proposed by Rigobon (2000) and find that it has power only when certain conditions are satisfied. In particular, the power of the test depends on the relative sizes of the sub-samples of low and high volatility, the relative degree of heteroscedasticity across these sub-samples, as well as the total number of observations. Interestingly, selecting parameters on the basis of our empirical estimations leads the limited-information methodology to reject the stability of the transmission mechanism with a probability of half when it should in fact be rejected with a probability of 0.95 . This result can be a first step in explaining the divergence of our results with those obtained by Rigobon (2001, 2002).

The existence of nonlinearities in the transmission of idiosyncratic shocks has important implications for portfolio management and the measurement of the potential benefits from international portfolio diversification. Firstly, changes in the transmission mechanism make it more difficult for portfolio managers to rebalance their portfolios optimally. Secondly, a usual approach to discuss the benefits of diversification relies on a consideration of cross-market correlations. It has been argued that since correlations increase during periods of crises, these benefits become reduced just when they are most needed. Our results show that such statements are incomplete since changes in market comovements in times of high turbulence are not unidirectional. Further research should assess the implications of our results for the empirical measurement of the benefits of international portfolio diversification. 


\section{Introduction and motivation}

During the last decade international financial markets have been affected by several major currency and financial crises. Indeed, we have recently celebrated the tenth anniversary of the speculative attacks on the parities of the Exchange Rate Mechanism in Europe in September 1992. Other famous examples include the 1994/95 Mexican "Tequila" crisis, the 1997/98 Asian flu, the 1998 Russian virus followed by the Brazilian crisis in early 1999. Lately, the collapse of the Turkish stabilization strategy and the eventual abandonment of the Argentinean currency board ended a ten-year series of severe crises in foreign exchange and financial markets.

Currency and financial crises are certainly not a new phenomenon. However, the apparent high degree of international transmission of these crises has triggered a large research effort both at the theoretical and empirical levels. The keyword is contagion. The empirical literature focuses on two related sets of issues. The first set of issues deals with the channels through which country-specific shocks such as sharp devaluations are propagated across borders. The goal is mainly to discriminate between different explanations for contagion: trade and financial linkages, macroeconomic similarities, common lender effects, common external shocks, etc. The second set of issues deals with the existence of contagion per se. In this context, contagion is defined as a significant change in the way that country-specific shocks are transmitted internationally ${ }^{1}$. Alternatively, we can interpret contagion as a rejection of the null hypothesis that the transmission mechanism is stable across tranquil periods and episodes of high financial turbulence.

It makes a lot of sense to adopt this definition of contagion. The process of globalization has reinforced the various linkages between open economies, making these more interdependent. Therefore, testing whether shocks are transmitted across borders or not does not make much sense. Any international macroeconomic model would allow for an analysis of the impact of external shocks on the domestic economy. A more interesting question is whether the strength of the transmission mechanism through which large country-specific shocks are transmitted remains stable over time. This is the central question of the contagion literature. It is this question that lies at the core of this paper.

There are at least two important reasons which motivate the empirical assessment of the stability of the propagation mechanism. Firstly, financial market participants benefit from international portfolio diversification. The process of globalization offers new investment opportunities. To the extent that economic and political shocks are mostly seen as idiosyncratic, investing in a higher number of countries allows for a reduction in risk exposure. In this context, the key variable is the correlation across

\footnotetext{
${ }^{1}$ Contagion carries the implicit meaning that cross-market linkages should be stronger in periods of high turbulence. This view is limiting in the sense that country-specific shocks could also weaken these linkages. Allowing for a change and not specifically an increase will be important in empirical work, as we shall see.
} 
financial markets. Therefore, if the strength of the transmission mechanism of idiosyncratic shocks changes when such large shocks occur in one country, the benefits of international diversification will be modified. It must be noted that correlations may not necessarily increase but they could also decrease. If we consider a geographical region consisting of strong and weak countries, as defined by their macroeconomic fundamentals, it could be the case that investors pull their funds out of weak countries into strong countries. As a consequence, the degree of covariation among financial markets would become lower. In any case, portfolio management requires knowledge of the degree of comovements among financial markets, and changes in the strength of these comovements will have important effects.

Secondly, and more controversially, testing for the stability of the propagation mechanism is also important as far as interventions by multilateral institutions are concerned. Some scholars have argued that if country-specific shocks are transmitted along the usual channels of interdependence across countries, without any sort of nonlinearity, then the spread of a crisis is only the result of globalization and thus, there is no motivation for public intervention, either by the International Monetary Fund or industrialised countries.

Early analyses of the existence of contagious effects focus on changes in correlation coefficients. This measure, however, suffers from numerous adjustment problems. Moreover, it does not properly model the interdependence across international financial markets. Consequently, recent research builds upon ad-hoc structural models of simultaneous equations which aim is to properly account for interdependencies between financial markets, so as to avoid a spurious detection of contagion. The estimation of such models is not without problems, most notably because of identification problems. However, Rigobon (2000) proposes an innovative procedure which does not require any arbitrary restrictions on the econometric specification but uses the heteroscedastic feature of the financial time series. The central idea is to use the heteroscedasticity to identify different volatility regimes and to classify the observations accordingly so as to build an instrumental variable. A test for the existence of contagion is then simply a test for the validity of the constructed instrument. Rigobon (2001, 2002) applies this approach to emerging market countries and concludes in favour of the stability of the transmission mechanism.

An alternative approach, pioneered by Favero and Giavazzi (2002), also makes use of a structural model of interdependence. However, rather than relying on an instrumental-variable estimation procedure, it starts by estimating the reduced-form model, which turns out to be a vector-autoregression specification, to identify countryspecific shocks. These are then included into the structural model which is estimated using a full-information procedure, making arbitrary restrictions on the lag structure to obtain identification. A test for contagion is simply a test of whether shocks in one country have a significant coefficient in the equations for other countries, having controlled for interdependence. Favero and Giavazzi (2002) apply this approach in the context of the parities of the Exchange Rate Mechanism in the early nineties and 
find widespread evidence of rejection of the stability of the propagation mechanism.

This paper pursues two objectives. Firstly, we apply the full-information methodology to a sample of emerging market countries. More precisely, we test for the existence of contagion during the Asian crisis for a sample of five south-east Asian stock markets. In contrast with Rigobon (2002), we uncover strong evidence against the stability of the transmission mechanism. Country-specific shocks are propagated across countries in a nonlinear way. Positive shocks can have either a positive or a negative impact on other stock markets, whereas negative shocks have a more systematic negative effect on other stock markets. This points towards the existence of an asymmetric international transmission of country-specific extreme events.

Secondly, since the empirical results about the existence of contagion depend upon the chosen methodology, we follow Favero and Giavazzi (2002) and integrate the two approaches within a common framework of analysis. Then, we make use of Monte Carlo simulations to determine the source of these diverging results. We find that the limited-information approach is appropriate only when certain conditions are satisfied. In particular, the power of the test proposed by Rigobon (2000) depends on the relative sizes of the sub-samples conditional on volatility, the relative degree of heteroscedasticity across these sub-samples, as well as the total number of observations. Since this methodology features applications in various fields of economics, it remains very important to assess its limitations, especially with respect to data availability.

The paper is organised as follows. Section 2 presents an non-exhaustive survey of the literature on contagion. Section 3 describes the full-information framework of Favero and Giavazzi (2002) and discusses some implications of the specification of the null hypothesis. Section 4 deals with the choice of the data and sample period. Section 5 presents the empirical results about the existence of contagion. Section 6 presents our Monte Carlo simulations while section 7 concludes.

\section{Survey of the literature}

This section provides a non-exhaustive survey of the literature on contagion. We develop a chronological view of the evolution of the literature and present the central references for each state of improvement of the methodologies that have been used ${ }^{2}$.

\subsection{The early literature: a signal extraction approach}

The early studies on the existence of contagion appear after the 1987 stock market crash in the United States and the simultaneous collapse of several other stock markets, despite significantly different economic conditions. The seminal reference is

\footnotetext{
${ }^{2}$ Claessens, Dornbusch and Park (2000) provide a broad overview of the contagion literature. For an enlightening organising framework of the channels of financial contagion, see Pritsker (2001). Rigobon (2001) discusses the various methodologies that have been adopted to test for the existence of contagion.
} 
King and Wadhwani (1990). They construct a signal extraction model where rational agents face imperfect information. Investors have access to different information sets and therefore, they are able to infer valuable information from price changes in other markets. Suppose two countries, 1 and 2. The change in the (log of the) stock market index, written as $s$, is related to systematic information, $u$, and idiosyncratic information, $v$. Whereas the former type of information affects both countries, the latter is by definition relevant only to one country. Under imperfect information, the generating process for changes in stock prices is given by

$$
\begin{aligned}
& s_{1, t}=u_{1, t}+\alpha_{12} E_{1}\left(u_{2, t}\right)+v_{1, t} \\
& s_{2, t}=\alpha_{21} E_{2}\left(u_{1, t}\right)+u_{2, t}+v_{2, t}
\end{aligned}
$$

where $E_{1}($.$) and E_{2}($.$) stand for the expectations operator conditional upon infor-$ mation observed in markets 1 and 2, respectively. It is thus assumed that the only information available to market $i$ about the value of $u_{j}$ is $s_{j}$. Investors in market 1 cannot determine whether some realization of $s_{2}$ occurs because of an idiosyncratic news, through $v_{2, t}$, or because of a systematic effect, through $u_{2, t}$.

Solving this signal extraction problem and computing the variances of $s_{1, t}$ and $s_{2, t}$, we obtain that the variances are larger in the case of perfect information than in that of imperfect information. Therefore, the correlation coefficient will be larger in the latter case. Consider the impact of an idiosyncratic shock in one market on the price in the other market. In the case of perfect information, this shock has no impact on the other market since agents know that it is relevant only to one market. However, in the case of imperfect information, because investors cannot distinguish whether the change in the price stems from systematic or idiosyncratic information, this shock has an impact, so that the two markets move together.

This theoretical model shows why markets should move together for reasons unrelated to country-specific economic fundamentals. King and Wadhwani (1990) hypothesize that in times of increased volatility, investors will place a greater weight on price changes in other stock markets. Therefore, the empirical prediction is that the correlation coefficient between two markets should increase following the occurrence of a large idiosyncratic shock. King and Wadhwani (1990) use hourly data for stock price changes in the United States, Japan and the United Kingdom for the period from September 1987 to November 1987. They find evidence of contagion, defined as a significant increase in correlation coefficients, after the collapse of the Dow Jones. Bertero and Mayer (1990) extend the analysis to a sample of 23 industrialised countries and emerging market countries, using daily data. They also find that correlation coefficients increase appreciably following the stock market crash in the United States.

The first applications of correlation analysis to emerging market economies focus on the 1994/95 Mexican crisis and the 1997/98 Asian flu. Calvo and Reinhart (1996) look at cross-country correlations between weekly stock market returns. The sample 
includes seven Latin American countries and six south-east Asian countries. They find that correlations among returns increase during the period following the devaluation of the Mexican peso. They also examine cross-country correlations between total returns on Brady bonds and conclude again that these increase markedly after the Mexican currency crisis. Baig and Goldfajn (1999) examine cross-country correlations among currencies, stock markets, interest rates and sovereign spreads of five south-east Asian economies, namely Thailand, Malaysia, Korea, the Philippines and Indonesia. They find strong evidence of contagion in foreign exchange markets and among sovereign spreads, while the evidence in stock markets and among interest rates remains rather mixed.

\subsection{Pitfalls: the bias and the need for correcting}

In a series of innovating papers, Forbes and Rigobon (2001, 2002) show that looking at unadjusted correlation coefficients is not appropriate. The calculated correlation coefficient is an increasing function of the variance of the underlying asset return, so that when coefficients between a tranquil period and a crisis period are compared, the coefficient in the crisis period is biased upwards as volatility rises widely ${ }^{3}$.

We follow Baumann (2000) to illustrate the dependence of the correlation coefficient on volatility. The stock market returns of two countries 1 and 2 are related in the following way, assuming no problem of endogeneity or omitted variable:

$$
s_{2, t}=\alpha+\beta s_{1, t}+\varepsilon_{t}
$$

where the error term has a zero mean and constant variance, and $E\left(s_{1, t} \varepsilon_{t}\right)=0$. The correlation coefficient is obtained as

$$
\rho=\beta \sqrt{\frac{\sigma_{s_{1}}^{2}}{\beta^{2} \sigma_{s_{1}}^{2}+\sigma_{\varepsilon}^{2}}}
$$

Differentiating $\rho$ with respect to $\sigma_{s_{1}}^{2}$, we get

$$
\frac{\partial \rho}{\partial \sigma_{s_{1}}^{2}}=\frac{1}{2} \beta \frac{\sigma_{\varepsilon}^{2}}{\sigma_{s_{1}} \sigma_{s_{2}}^{3 / 2}}>0
$$

For absolute values of the correlation coefficient this derivative is unambiguously positive and hence, the correlation coefficient is biased upwards and requires an adjustment. Forbes and Rigobon (2002) revisit the early literature and test for the existence of contagion during the 1997/98 Asian crisis, the 1994/95 Mexican crisis and the 1987 stock market crash in the United States. When unadjusted correlation coefficients are computed, there is ample evidence of rejection of the null hypothesis of equality of these coefficients across tranquil and crisis periods. However, adjusted

\footnotetext{
${ }^{3}$ See also Boyer, Gibson and Loretan (1999) and Dungey and Zhumabekova (2001).
} 
correlation coefficients yield the famous result "no contagion, only interdependence". In other words, contagion does not exist.

Loretan and English (2000) explore the relationship between correlations and increases in volatility in crises periods. They assess to what extent the increase in correlation coefficients at times of market turbulence can be explained by the inherent increase in volatility. The results point to the fact that increases in correlation coefficients stem from the higher volatility of asset returns in crises periods, thereby corroborating the results obtained by Forbes and Rigobon (2002).

The adjustment procedure has in turn been questioned and at least two papers cast some light on its inadequacy. Baumann (2000) recalls that the procedure is based on a model of asset returns which explicitly disregards the issue of endogeneity. In effect, a simple model of asset return determination would augment equation (3) with a corresponding equation for $s_{1}$. Baumann (2000) computes the correlation coefficient in the case of simultaneous equations. There is still a bias but its direction can be positive or negative depending on the parameters of the structural model. Therefore, the adjustment proposed by Forbes and Rigobon (2002) should be taken with extreme caution since it relies upon an assumption of exogeneity which is clearly doubtful.

Corsetti, Pericoli and Sbracia (2002) build a factor model of asset returns and show that the correction procedure of Forbes and Rigobon (2002) relies on arbitrary assumptions about the variance of the country-specific shocks where the crisis originates. The factor model is written as

$$
\begin{aligned}
& s_{1}=\alpha_{1}+\gamma_{1} f+\varepsilon_{1} \\
& s_{2}=\alpha_{2}+\gamma_{2} f+\varepsilon_{2}
\end{aligned}
$$

where $f$ is a common factor affecting both returns and $\varepsilon_{1}$ and $\varepsilon_{2}$ are countryspecific shocks. We will assume that the crisis $C$ originates in country 2 , so that

$$
\begin{aligned}
\operatorname{Var}\left(s_{2} \mid C\right) & =(1+\delta) \operatorname{Var}\left(s_{2}\right), \quad \delta>0 \\
\operatorname{Var}\left(\varepsilon_{1} \mid C\right) & =\operatorname{Var}\left(\varepsilon_{1}\right)
\end{aligned}
$$

Solving equations (6) and (7) for the common factor, equating the obtained results and solving for $s_{1}$, we get

$$
\begin{aligned}
& s_{1}=\left(\alpha_{1}-\alpha_{2} \frac{\gamma_{1}}{\gamma_{2}}\right)+\frac{\gamma_{1}}{\gamma_{2}} s_{2}+\left(\varepsilon_{1}-\frac{\gamma_{1}}{\gamma_{2}} \varepsilon_{2}\right) \\
& s_{1}=\alpha+\beta s_{2}+\varepsilon
\end{aligned}
$$

which is equivalent to the basic specification (3) of Forbes and Rigobon (2002). The assumptions underlying equation (11) are, as before, that 


$$
\begin{aligned}
\operatorname{Cov}\left(s_{2}, \varepsilon \mid C\right) & =\operatorname{Cov}\left(s_{2}, \varepsilon\right)=0 \\
\operatorname{Var}(\varepsilon \mid C) & =\operatorname{Var}(\varepsilon)
\end{aligned}
$$

Firstly, if $s_{2}$ reflects idiosyncratic noise, so that $\operatorname{Var}\left(\varepsilon_{2}\right)>0$, then $\operatorname{Cov}\left(s_{2}, \varepsilon\right)$ is not equal to zero, thereby violating (12). Secondly, if $\operatorname{Var}\left(\varepsilon_{2}\right)$ increases during the crisis period, then the other assumption (13) is also violated. Therefore, the analysis provided by Forbes and Rigobon (2002) is only valid under the unrealistic assumption that $\operatorname{Var}\left(\varepsilon_{2}\right)$ is equal to zero. Consequently, the ratio between this variance of the idiosyncratic shock in country 2 and the variance of the common factor will be equal to zero. Corsetti, Pericoli and Sbracia (2002) build a "theoretical" correlation coefficient under the null hypothesis of no contagion, which is to be compared with the correlation coefficient in the crisis period. The former coefficient depends on the ratio between the variance of the idiosyncratic shock and that of the common factor. Since this ratio is assumed to be zero, as explained above, the test of Forbes and Rigobon (2002) will be biased towards not rejecting the null hypothesis. Hence, it is not surprising that studies making use of adjusted correlation coefficients find almost no evidence of contagion ${ }^{4}$.

\subsection{The recent contributions}

Apart from the numerous adjustment problems associated with the analysis of correlation coefficients, the methodologies presented so far abstract from the problem of endogeneity between asset returns. This modelling strategy is not satisfactory. Any analysis of the propagation of shocks between Thailand and Malaysia should allow for two-way interdependencies. Restrictions on the contemporaneous relationships across international stock markets are not appropriate and should not be used ${ }^{5}$.

Therefore, the recent contributions make use of ad-hoc structural systems of simultaneous equations. A simple model of asset returns would be specified as, in deviations form

$$
\begin{aligned}
& s_{1, t}=\beta s_{2, t}+\varepsilon_{t} \\
& s_{2, t}=\alpha s_{1, t}+\eta_{t}
\end{aligned}
$$

\footnotetext{
${ }^{4}$ Corsetti, Pericoli and Sbracia (2002) provide some estimates of the variance ratios. These are typically contained in an interval between 2 and 4, thereby being significantly higher than the implicitly assumed value of zero in Forbes and Rigobon (2002).

${ }^{5}$ As an exception, we note that stock markets around the world are not open at the same time. In other words, trading time asymmetries imply, for example, that Brazil's stock return depends on today's Russian return, whereas Russia's return depends on yesterday's Brazilian return. This feature would allow for a recursive system of simultaneous equations. In this case, setting a zero restriction on the contemporaneous effect of the Brazilian market on the Russian market is appropriate and ordinary least squares yield consistent parameter estimates.
} 
where neither $\beta$ or $\alpha$ are restricted to be zero, and $\varepsilon_{t}$ and $\eta_{t}$ are country-specific shocks. In this case, this system is unidentified and as such, it is impossible to obtain parameter estimates for $\beta$ and $\alpha$. Two recent contributions propose solutions to this problem of identification. The rest of this section describes briefly the innovative approach proposed by Rigobon (2000). The next section discusses in more details the methodology introduced by Favero and Giavazzi (2002) which is used to test for the existence of contagion in the context of the 1997/98 Asian crisis.

Rigobon (2000) provides an instrumental-variable methodology to test for contagion. The basic specification can be written in the bivariate case as (14) and (15), which already assumes normalization of the matrix of coefficients on the contemporaneous variables, and orthogonalization of the country-specific shocks. Importantly, it is also assumed that the country where the crisis originates is known. Since the system of equations is not identified, we cannot obtain parameter estimates for the coefficients and we cannot assess whether they are stable over time.

However, suppose that the data are characterized by two regimes of volatility, low and high, and that the increase in volatility across regimes is entirely the consequence of an increase in the variance of one of the two country-specific shocks. In this case, we can split the whole sample into two sub-samples according to the volatility regime. Rigobon (2000) constructs an instrumental variable for $s_{2}$ in equation (14) of the form $^{6}$

$$
w_{t}=\left(\begin{array}{c}
\frac{s_{2, t}^{h}}{T_{s_{2, t}^{h}}^{l}} \\
-\frac{s^{l}}{T^{l}}
\end{array}\right)
$$

The corresponding instrumental-variable estimator is simply given by

$$
\widehat{\beta}=\left(w^{\prime} s_{2}\right)^{-1} w^{\prime} s_{1}
$$

and this estimator satisfies the necessary conditions under the null hypothesis of no contagion ${ }^{7}$. Therefore, a test for the existence of contagion is simply implemented as a Hausman-type test for the validity of the instrument $w_{t}$.

Rigobon (2001) uses this methodology to test for the stability of the propagation mechanism of shocks across stock and bond markets, for a sample of fourteen Latin American and south-east Asian countries. The central finding is that the transmission channel is remarkably stable for stock markets, whereas there is some limited evidence of instability of parameters in bond markets. Rigobon (2002) focuses on a wider sample of thirty-six industrialised and emerging market economies and concludes that "the high comovement across international stock markets is not the result of changes in the propagation mechanism, but the outcome of strong interdependence

\footnotetext{
${ }^{6}$ The construction of an instrument for $s_{1}$ is completely symmetric and thus, it is omitted here.

${ }^{7}$ The two usual conditions for the validity of an instrument are that this instrument should be correlated with the original variable that it replaces, but uncorrelated with the error term.
} 
among these markets that is present at all times" ${ }^{\text {. }}$

In the next section we discuss another approach to testing for the existence of contagion that also relies upon a structural model of interdependence. Then, we apply this alternative methodology to the 1997/98 Asian crisis in order to assess the stability of the transmission mechanism.

\section{Econometric specification}

Favero and Giavazzi (2002) propose a three-step procedure to testing for nonlinearities in the propagation mechanism of country-specific shocks ${ }^{9}$. The first step is to estimate a reduced-form vector-autoregression model and to identify with dummy variables large residuals as country-specific shocks. The second step is to estimate the structural model of interdependence, including the dummy variables, and making some arbitrary assumptions on the lag structure to obtain identification. Finally, we can test for the existence of contagion.

We start with the following dynamic structural model of interdependence:

$$
B S=\Gamma(L) S+E
$$

where $S$ is a vector of stock market returns and $B$ is a non-diagonal matrix of coefficients on the contemporaneous effects. It is well known that the reduced form of a general dynamic structural model can be expressed as a vector-autoregressive specification $^{10}$. Premultiplying the terms in (18) by $B^{-1}$, we get

$$
\begin{aligned}
& B^{-1} B S=B^{-1} \Gamma(L) S+B^{-1} E \\
& S=\Pi(L) S+B^{-1} E \\
& B^{-1} E=\left(\begin{array}{l}
u_{1, t} \\
u_{2, t}
\end{array} \mid I_{t-1}\right) \sim\left[\left(\begin{array}{l}
0 \\
0
\end{array}\right), \Sigma_{t}\right]
\end{aligned}
$$

where the residuals in (20) are heteroscedastic and non-normal. Therefore, the sample may include episodes of high market turbulence. These are captured by dummy variables, thereby eliminating heteroscedasticity and non-normality. Focusing on the bivariate case for clarity of exposition and assuming an optimal lag length of one, we can rewrite the VAR specification as

\footnotetext{
${ }^{8}$ Rigobon (2002), p. 2

${ }^{9}$ Favero and Giavazzi (2002) use the term "nonlinearities" to refer to the phenomenon of contagion. The reason is to avoid the implicit meaning of contagion as a significant reinforcement in cross-market relationships during episodes of high market turbulence. In fact, significant reductions in these relationships should also be interpreted as contagion.

${ }^{10}$ See, for example, Hamilton (1994), p.326.
} 


$$
\begin{aligned}
\left(\begin{array}{l}
s_{1, t} \\
s_{2, t}
\end{array}\right) & =\left(\begin{array}{ll}
\pi_{11} & \pi_{12} \\
\pi_{21} & \pi_{22}
\end{array}\right)\left(\begin{array}{l}
s_{1, t-1} \\
s_{2, t-1}
\end{array}\right)+B^{-1}\left(\begin{array}{c}
\epsilon_{1, t} \\
\epsilon_{2, t}
\end{array}\right) \\
\left(\begin{array}{l}
\epsilon_{1, t} \\
\epsilon_{2, t}
\end{array}\right) & =\left(I+\left(\begin{array}{ll}
a_{11} & a_{12} \\
a_{21} & a_{22}
\end{array}\right)\left(\begin{array}{cc}
d_{1, t} & 0 \\
0 & d_{2, t}
\end{array}\right)\right)\left(\begin{array}{c}
\epsilon_{1, t}^{l} \\
\epsilon_{2, t}^{l}
\end{array}\right) \\
\left(\begin{array}{c}
\epsilon_{1, t}^{l} \\
\epsilon_{2, t}^{l}
\end{array}\right) & \sim N\left[\left(\begin{array}{l}
0 \\
0
\end{array}\right), \Sigma\right]
\end{aligned}
$$

The partitioning of the matrix containing the dummy variables is conditional on the country in which the shock originates. Moreover, $\epsilon_{1, t}^{l}$ and $\epsilon_{2, t}^{l}$ are the structural shocks in periods of low volatility. The off-diagonal blocks of the matrix $A$ allow for nonlinearities in the propagation of shocks between countries. Therefore, a simple test for the absence of nonlinearities specifies the following null hypothesis:

$$
H_{0}: a_{i j}=0, \forall i \neq j
$$

The estimation of the reduced-form model (20) is the first step of the methodology. Then, large residuals are defined as events and represented by dummy variables. Again, this allows to filter out heteroscedasticity and non-normality. The second step is to estimate the structural model of interdependence. Unfortunately, this system of simultaneous equations is not identified. To remedy this problem, some restrictions are imposed. Because the general-to-specific approach is followed, it is more appropriate to restrict the coefficients on the lagged endogenous variables than on the contemporaneous feedbacks. Therefore, the own lagged dependent variable is assumed to be sufficient to capture the structural dynamics ${ }^{11}$, i.e. $\gamma_{i j}=0, \forall i \neq j$. In this way, the system of equations is exactly identified as each equation in the system is itself identified.

One remark is worth mentioning. The specification of the null hypothesis in this framework is more general than in earlier analyses of correlation coefficients. Favero and Giavazzi (2002) adopt the following hypothesis to test for the existence of contagion:

$$
H_{0}: a_{12}=a_{21}=0
$$

In contrast, the core idea of the former correlation approach is a comparison of the correlation (or covariance) between two asset returns during a relatively stable period to that during a period of turbulence. In that context, contagion is defined as a significant increase in the cross-market correlation during the period of turmoil. In terms of the full-information approach, the alternative hypothesis would be that $a_{12}$

\footnotetext{
${ }^{11}$ This assumption is not uncontroversial. Rigobon (2001) argues that the theoretical foundations are extremely weak. Consider two countries, home and foreign. If it is true that the home returns are explained by current foreign as well as past home returns, it seems reasonable that past foreign returns should also have some explanatory power for current home returns.
} 
or $a_{21}$ or both are strictly greater than zero. However, when testing for nonlinearities, we allow for a more general alternative hypothesis which is that either $a_{12}$ or $a_{21}$ or both are different from zero. In particular, these could be significantly negative, as we shall see.

Finally, there is accumulating evidence that the economic policies followed by major industrialised countries have a large impact on the economies of emerging market countries. In a seminal paper on the determinants of capital flows to Latin America between the end of the "lost decade" and the early nineties, Calvo, Leiderman and Reinhart (1993) find that the large increase in capital inflows is partly due to external factors, such as lower international interest rates and the recession in the United States. Indeed, they argue that "some of the renewal of capital flows to Latin America results from external factors and can be considered an external shock common to the region" 12 . In a premonitory discussion on the policy implications of these results, they conclude that "the importance of external factors suggests that a reversal of those conditions [outside the region] may lead to a future capital outflow, increasing the macroeconomic vulnerability of Latin American economies" ${ }^{13}$.

Recent studies confirm that international factors are important determinants of the economic situation of emerging market countries. Frankel, Schmukler and Serven (2002) find that these economies exhibit high sensitivity to international interest rates, especially under fixed exchange rate regimes. Reinhart and Reinhart (2001) present stylized facts on the impact of economic conditions in the United States on emerging markets. They conclude that economic downturns in the United States have adverse consequences on emerging markets, in particular for those whose export share to the United States is large. Moreover, capital flows to emerging markets increase markedly in years when U.S. monetary policy is easing, thereby corroborating the results obtained by Calvo, Leiderman and Reinhart $(1993)^{14}$.

The significant impact of common externals shocks has an empirical implication. If these are not taken into account, one may conclude wrongly that a crisis in one country is transmitted to other countries, while the shock is actually external and common to all the countries. We model common shocks explicitly by introducing a matrix $C$ of so-called monsoonal variables into the model of interdependence, so that the structural model is now given by

$$
B S=\Gamma(L) S+\Psi C+E
$$

and the reduced-form model is obtained as

\footnotetext{
${ }^{12}$ Calvo, Leiderman and Reinhart (1993), p. 109

${ }^{13}$ Calvo, Leiderman and Reinhart (1993), p. 108

${ }^{14}$ Frankel and Roubini (2001) discuss the various ways in which macroeconomic policies followed by industrial countries can impact on emerging markets. Evidence on the effect of common external shocks on the incidence of currency crises can be found in Frankel and Rose (1996), Milesi-Ferretti and Razin (1998) and Moreno and Trehan (2000).
} 


$$
\begin{aligned}
B^{-1} B S & =B^{-1} \Gamma(L) S+B^{-1} \Psi C+B^{-1} E \\
S & =\Pi(L) S+\Theta C+B^{-1} E
\end{aligned}
$$

This extended specification allows to capture common external shocks separately. Therefore, when constructing the dummy variables which capture events, we retain only purely country-specific events.

\section{Data}

We test for the existence of contagious effects in the context of the 1997/98 Asian crisis. The sample contains five south-east Asian countries, namely the Philippines, Korea, Malaysia, Thailand and Indonesia and it extends from 1st January 1996 to 31st July 1998. The choice for this period is motivated by the fact that there were no other large-scale currency or financial crisis in emerging market economies. If our sample would overlap with some other crisis episode, it would imply a need for modelling the impact of this other crisis on the south-east Asian region.

We make use of data at the daily frequency. All the data are retrieved from Datastream. Stock market indices are expressed in local currency and as calculated by the International Finance Corporation (IFC). These indices are intended to represent the performance of the most active stocks in their respective stock markets and to be the broadest possible indicator of market movements. The present coverage of such indices exceeds $75 \%$ of total market capitalization. We transform these variables into stock market returns through log-differentiation ${ }^{15}$.

The question of the currency denomination of the returns remains controversial. On the one hand, it is usually asserted that foreign investors care about returns expressed in their own currency. Arbitrage yields a parity condition whereby the domestic return equals the foreign return plus expected depreciation. In this case, we would make use of stock market returns in foreign currency. On the other hand, focusing on returns in local currency allows to eliminate the exchange rate component of the return. Such a choice is motivated by the fact that exchange rate changes could offset variations in the stock market return in local currency. We provide a simple example of this dilemma. Figure 1 represents the evolution of the Thai stock market return in bahts and in U.S. dollars.

It is well known that the Thai stock market experienced a massive surge following the announcement of the devaluation of the baht. This is well reflected by the index expressed in bahts. However, the large size of the devaluation leads to a moderate fall in the index expressed in U.S. dollars. Therefore, looking at indices expressed in

\footnotetext{
${ }^{15}$ It can be argued that log-differentiation is only an approximation to the true percentage change. We also used stock market returns obtained as true percentage changes. The results remain unaffected and are therefore not reported.
} 


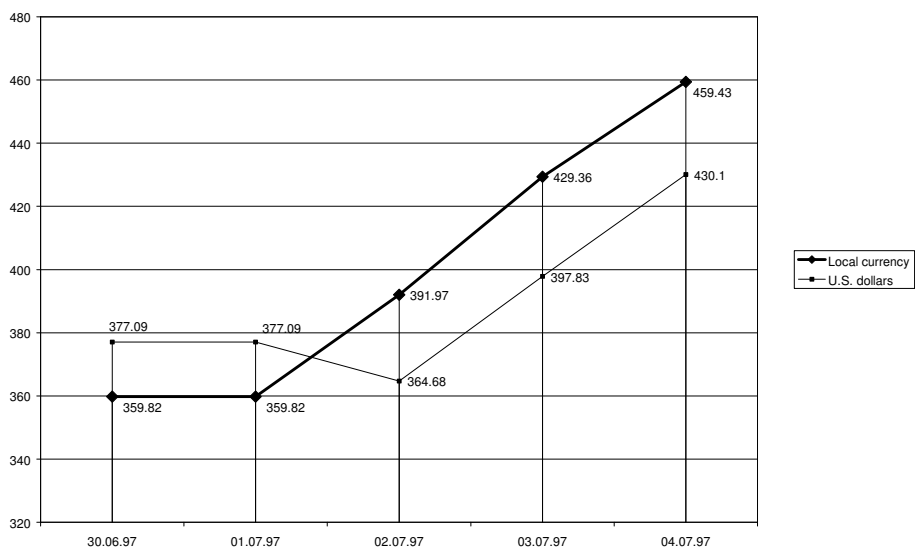

Figure 1: Thai stock market indices expressed in bahts and U.S. dollars

foreign currency can be misleading whenever the index expressed in local currency and the exchange rate move in opposite directions. This paper makes use of stock market returns expressed in local currency.

We also select variables standing for common external shocks. Following the studies devoted to this issue, we augment the basic specification with log-differentiated series of the three-month U.S. Treasury bill interest rate, the U.S. stock market and the yen/U.S. dollar exchange rate. Corsetti, Pesenti and Roubini (1999) have argued that "the sharp appreciation of the U.S. dollar relative to the Japanese yen and the European currencies since the second half of 1995 led to deteriorating costcompetitiveness in most Asian countries whose currencies were effectively pegged to the dollar" 16 .

\section{Empirical results on the existence of contagion}

This section presents the results obtained from the full-information methodology proposed by Favero and Giavazzi (2002). Since the approach is articulated around three steps, we present the outcome of our analysis in three sub-sections.

\subsection{The reduced-form model}

The first step is to estimate the reduced form of the dynamic structural model. Again, this reduced-form model is simply a vector-autoregressive specification. Therefore, it is necessary to solve the preliminary problem of optimal lag length. We focus on various selection criteria, namely a sequential modified likelihood ratio test, the Akaike information criterion, and the Schwarz criterion ${ }^{17}$. As is often the case in

\footnotetext{
${ }^{16}$ Corsetti, Pesenti and Roubini (1999), p. 308-309.

${ }^{17}$ The modified LR statistic relies on the small sample modification proposed by Sims (1980).
} 
empirical research, these statistics give different optimal lag lengths. If we use a hypothesized maximum lag length of five, then the likelihood ratio test and the Akaike criterion select five lags, whereas the Schwarz criterion selects one lag. If we extend the hypothesized maximum length to twenty, the likelihood ratio test selects twenty and the Akaike criterion fourteen, whereas the Schwarz criterion still selects one lag.

In fact, the last two lag selection criteria yield a number representing the trade-off between goodness-of-fit and parsimony. The lag length corresponds to the minimum of these numbers. An increase in the lag order contributes to lowering this number as it decreases the error sum of squares, but contributes to increasing it as the addition of lags is penalized because of the desirability of parsimony. Since the Schwarz criterion penalizes more the addition of lags in a model specification, it is not surprising that it selects a lower number of lags. In the end, since we will estimate a large structural model and given the sensitivity of both the likelihood ratio test and the Akaike criterion to the hypothesized maximum lag length, we rely on the Schwarz criterion and adopt a unit optimal lag length.

To identify country-specific shocks we examine the residuals of the estimated VAR model. These are heteroscedastic and as such, they contain episodes of high market turbulence. We assign dummy variables to residuals which are three times greater the standard deviation of residuals. Therefore, these dummies will capture extreme country-specific events. The choice for the threshold value of 3 is motivated by parsimony and previous research. Making use of a threshold of 2 yields 190 countryspecific events and an equivalent number of dummy variables. Moreover, Gindraux (2002) provides a detailed sensitivity analysis for the threshold values and finds that the dummies that are selected by a threshold of 3 are those which typically survive the testing-down procedure to overidentify the structural system of equations in the second step of the methodology.

\begin{tabular}{||l|c|c|c|c|c||}
\hline \hline \multicolumn{7}{||l}{ Table 1: Number of shocks } \\
\hline \hline Country & Philippines & Korea & Malaysia & Thailand & Indonesia \\
\hline Shocks & 10 & 13 & 12 & 11 & 13 \\
\hline \hline
\end{tabular}

We obtain 59 country-specific shocks. The appendix provides the dates, countries, type of shock and the corresponding news retrieved from the online archives of Bloomberg. These shocks are mostly on the positive side: we identify 36 positive shocks and 23 negative shocks. Distinguishing between types of shocks is interesting as the degree and direction of transmission may be asymmetric, an issue to which we return in the third subsection.

Finally, we note that excluding common external shocks would yield 67 extreme events. Again, in the context of emerging market economies it is important to account for common external shocks in order to avoid thinking of an event as being contagious whereas all countries are in fact affected simultaneously by a common shock. 


\subsection{The structural model of interdependence}

The second step of the methodology is to estimate the dynamic structural model of simultaneous equations by three-stage least squares. The first specification is fully identified by the restriction on the lag structure that only the own lagged variable enters each equation. Then, in the spirit of the LSE approach, a simplification search is carried out, in which simpler cases are tested against the general model. Since these special cases are obtained by imposing restrictions on the parameters of the general models, a simple $F$ test is used to test whether these restrictions are actually valid. The simplification search, also called testing-down procedure, is carried out in a systematic way and stops whenever the restrictions are rejected by the data.

We start by testing the restriction that the coefficients on all the variables which are not significant in our initial fully identified specification are equal to zero. Since this restriction is largely rejected by the data, we look for combinations of restrictions which would not be rejected. Through a systematic analysis we reach a more parsimonious specification which, however, features a difficult problem. In the equations corresponding to the Philippines and to Indonesia, we cannot exclude the Malaysian stock market return as an explanatory endogenous variable. If we do not exclude this variable, then the coefficients on the differences of (the log of) the U.S. interest rate, the U.S. stock market index, and the yen/U.S. dollar exchange rate are not significantly different from zero, although they are highly significant in the other three equations. However, if we exclude it, then these three common external shocks become significant.

\begin{tabular}{|c|c|c|c|c|c|}
\hline & \multicolumn{5}{|c|}{ Dependent variable } \\
\hline & $s_{P H}$ & $s_{K O}$ & $s_{M Y}$ & $s_{T H}$ & $s_{I N}$ \\
\hline Constant & -0.0009 & -0.0019 & -0.0011 & -0.0029 & \\
\hline$s_{P H}$ & $\mathrm{X}$ & & & & \\
\hline$s_{K O}$ & & $\mathrm{X}$ & & 0.2992 & \\
\hline$s_{M Y}$ & & & $\mathrm{X}$ & & \\
\hline$s_{T H}$ & & & 0.2784 & $\mathrm{X}$ & \\
\hline$s_{I N}$ & & & & & $\mathrm{X}$ \\
\hline Lagged dep. var & 0.2293 & 0.1947 & 0.1017 & 0.1100 & 0.1226 \\
\hline U.S. interest rate & 0.2411 & 0.3079 & 0.1695 & & 0.2833 \\
\hline U.S. stock market & 0.4125 & 0.3366 & 0.3451 & 0.3557 & 0.5898 \\
\hline JPY/USD rate & & -0.2253 & -0.2232 & & -0.2113 \\
\hline Observations & 671 & 671 & 671 & 671 & 671 \\
\hline \multicolumn{6}{|c|}{$\begin{array}{l}\text { Coefficients in italics are significant at the } 10 \% \text { level. All other reported } \\
\text { coefficients are significant at the } 5 \% \text { level. Coefficients which are not } \\
\text { reported are not significant, either at the } 10 \% \text { or } 5 \% \text { level. }\end{array}$} \\
\hline
\end{tabular}


We conjecture that the common external shocks in these equations are highly collinear with the Malaysian stock market return. The model captures interdependence between Malaysia and both the Philippines and Indonesia while these countries are actually all affected by the external variables. In the end, we choose to drop the Malaysian stock market return in these two equations to remedy this problem.

The results in table 2 show little evidence of interdependence and a strong influence of common external shocks. We find interdependence from Thailand to Malaysia and from Korea to Thailand. Therefore, it seems that permanent cross-market linkages are very weak in normal tranquil times ${ }^{18}$. However, the economic situation in the United States impacts very forcefully on the south-east Asian region ${ }^{19}$. Most notably, the behaviour of the U.S. stock market has a significant positive effect: any increase in U.S. stock market returns yields an increase in south-east Asian returns. Moreover, higher interest rates in the United States have a consistently positive effect on the region, except for Thailand. Although we initially expected a negative sign consistent with Calvo, Leiderman and Reinhart (1993), we would argue that changes in the level of interest rates in the United States affect expectations to a significant extent. Such changes in expectations are not directly observable and therefore, we cannot determine unambiguously their impact on emerging stock market returns.

Finally, the yen/U.S. dollar exchange rate is important for Korea, Malaysia and Indonesia, with a negative sign indicating that a depreciation of the yen relative to the U.S. dollar represents a loss of competitiveness for these three countries. The reason why the Philippines and Thailand are not affected may be that their respective currencies were largely devalued early in the crisis.

\subsection{Testing for contagion}

We can now focus on the existence of contagion. Again, we interpret as evidence of nonlinearities the fact that coefficients on country-specific shocks in four other countries are significant in a given country equation. The null hypothesis of no nonlinearities can be conceptually thought of as a null hypothesis of no bold coefficients in table 3. It is readily seen that the null hypothesis is rejected ${ }^{20}$. Most of the country-specific events are transmitted across countries in a non-linear way.

\footnotetext{
${ }^{18}$ This result contrasts with the "only interdependence" part of the results obtained by Forbes and Rigobon (2002).

${ }^{19}$ Since we use log-differentiated time series, these coefficients are simply elasticities. A $1 \%$ change in the U.S. stock market return will trigger an $\mathrm{x} \%$ change in the south-east Asian return, where $\mathrm{x}$ is the reported coefficient.

${ }^{20}$ This result contrasts with the "no contagion" part of Forbes and Rigobon (2002).
} 


\begin{tabular}{|c|c|c|c|c|c|c|c|}
\hline \multicolumn{8}{|c|}{ Table 3: Existence of contagion } \\
\hline Date & Country & Type & $\overline{s_{P H}}$ & $s_{K O}$ & $s_{M Y}$ & $s_{T H}$ & $s_{I N}$ \\
\hline $07 / 10 / 96$ & TH & - & & & & -0.0657 & \\
\hline $18 / 11 / 96$ & TH & - & & & & -0.0630 & \\
\hline $02 / 07 / 97$ & $\mathrm{TH}$ & + & -0.0235 & & -0.0225 & 0.0811 & \\
\hline $03 / 07 / 97$ & TH & + & & & -0.0322 & 0.0811 & \\
\hline $11 / 07 / 97$ & $\mathrm{PH}$ & + & 0.0741 & & 0.0245 & -0.0412 & \\
\hline $28 / 08 / 97$ & PH,MY & - & -0.0813 & & -0.0781 & & -0.0438 \\
\hline $02 / 09 / 97$ & $\mathrm{TH}$ & + & & & & 0.0659 & \\
\hline $03 / 09 / 97$ & MY, IN &,-+ & & & -0.0579 & & 0.0742 \\
\hline $05 / 09 / 97$ & MY, IN & + & & & 0.1154 & 0.0407 & 0.1204 \\
\hline $23 / 10 / 97$ & $\mathrm{PH}$ & - & -0.0446 & & -0.0211 & & \\
\hline $29 / 10 / 97$ & IN & + & 0.0304 & & & & 0.0485 \\
\hline $03 / 11 / 97$ & $\mathrm{KO}, \mathrm{MY}$ & + & & 0.0782 & 0.0615 & & \\
\hline $18 / 11 / 97$ & MY & - & -0.0187 & & -0.0661 & & \\
\hline $20 / 11 / 97$ & MY & - & & & -0.0971 & & -0.0427 \\
\hline $24 / 11 / 97$ & $\mathrm{KO}$ & - & & -0.1137 & 0.0231 & & 0.0628 \\
\hline $04 / 12 / 97$ & $\mathrm{KO}$ & + & & 0.0754 & 0.0335 & & 0.0378 \\
\hline $08 / 12 / 97$ & MY & + & & -0.0505 & 0.0815 & 0.0358 & \\
\hline $09 / 12 / 97$ & MY & - & & -0.0604 & -0.0610 & & \\
\hline $15 / 12 / 97$ & $\mathrm{KO}$ & + & & 0.1205 & & & -0.0660 \\
\hline $23 / 12 / 97$ & $\mathrm{KO}$ & - & -0.0191 & -0.0857 & & & \\
\hline $26 / 12 / 97$ & $\mathrm{KO}$ & + & & 0.0703 & & -0.0400 & \\
\hline $08 / 01 / 98$ & IN & - & -0.0328 & 0.0397 & & -0.0533 & -0.1608 \\
\hline $09 / 01 / 98$ & $\mathrm{PH}$ & - & -0.0671 & & & & \\
\hline $12 / 01 / 98$ & $\mathrm{KO}$ & + & 0.0384 & 0.1209 & & -0.0599 & 0.0412 \\
\hline $13 / 01 / 98$ & IN & + & 0.0361 & & 0.0376 & 0.0479 & 0.0943 \\
\hline $15 / 01 / 98$ & IN & - & & 0.0617 & & -0.0420 & -0.0583 \\
\hline $16 / 01 / 98$ & $\mathrm{TH}$ & + & & -0.0385 & & 0.1057 & 0.0894 \\
\hline $19 / 01 / 98$ & $\mathrm{PH}, \mathrm{KO}, \mathrm{MY}, \mathrm{TH}$ & + & 0.0607 & 0.0953 & 0.0588 & 0.0796 & 0.0629 \\
\hline $30 / 01 / 98$ & $\mathrm{PH}, \mathrm{KO}, \mathrm{TH}$ & + & 0.0776 & 0.0788 & -0.0322 & 0.0981 & \\
\hline $02 / 02 / 98$ & PH, TH, IN & + & 0.0755 & -0.0354 & -0.0320 & 0.1238 & \\
\hline $03 / 02 / 98$ & $\mathrm{PH}, \mathrm{MY}, \mathrm{IN}$ &,,-+- & -0.0605 & & 0.1904 & & -0.1024 \\
\hline $04 / 02 / 98$ & $\mathrm{TH}$ & - & & & & -0.1038 & \\
\hline $05 / 02 / 98$ & MY, TH & + & & & 0.0384 & 0.0746 & \\
\hline $11 / 02 / 98$ & PH, IN &,+- & 0.0538 & -0.0350 & & & -0.0928 \\
\hline $12 / 02 / 98$ & IN & - & -0.0316 & & -0.0614 & & -0.1112 \\
\hline $10 / 03 / 98$ & MY & + & & 0.0494 & 0.0507 & & \\
\hline $26 / 03 / 98$ & IN & + & & & & & 0.0769 \\
\hline $04 / 05 / 98$ & $\mathrm{KO}$ & - & & -0.0760 & & & \\
\hline $13 / 05 / 98$ & IN & - & -0.0220 & & & -0.0373 & -0.0955 \\
\hline $19 / 05 / 98$ & IN & + & -0.0231 & & & & 0.0931 \\
\hline $12 / 06 / 98$ & $\mathrm{KO}$ & - & 0.0206 & -0.0747 & & & \\
\hline $17 / 06 / 98$ & $\mathrm{KO}$ & + & & 0.0802 & & 0.0527 & 0.0443 \\
\hline $19 / 06 / 98$ & $\mathrm{PH}$ & - & -0.0457 & -0.0580 & & & \\
\hline $20 / 07 / 98$ & $\mathrm{KO}$ & + & -0.0274 & 0.1006 & & & \\
\hline $\begin{array}{l}\text { Coefficien } \\
\text { coefficient } \\
\text { are not si\& } \\
\text { to dummi }\end{array}$ & $\begin{array}{l}\text { in italics are signi } \\
\text { rre significant at } \\
\text { ficant, either at th }\end{array}$ & $\begin{array}{l}\text { t at } \\
\% \text { lev } \\
\% \text { or }\end{array}$ & $\begin{array}{l}10 \% \text { level } \\
\text { Coefficien } \\
\text { o level. B }\end{array}$ & $\begin{array}{l}\text { All other } \\
\text { s which ar } \\
\text { d coefficie }\end{array}$ & $\begin{array}{l}\text { ported } \\
\text { hot repo } \\
\text { corresp } \\
\text { puntries. }\end{array}$ & & \\
\hline
\end{tabular}

In other words, the propagation mechanism is not stable over time. Moreover, positive or negative shocks do not necessarily imply positive or negative reactions, respectively, of other stock markets ${ }^{21}$. For example, although the devaluation of the

\footnotetext{
${ }^{21}$ Since the reported coefficients are those of dummy variables, and since the dependent variable is a percentage change, we can interpret the values of the coefficients as percentage changes in other markets following an event in some given country. For example, the devaluation of the Thai baht on 2nd July 1997 contributes to a reduction of $2.35 \%$ in the Philippine stock market.
} 
Thai baht on 2nd July 1997 leads to a surge in Thailand's stock market, it triggers a fall in the Philippine and Malaysian stock markets. Otherwise, stock markets may collapse together. For example, on 12th February 1998 Stanley Fischer, at the time Deputy Managing Director of the IMF, says that Indonesia is not ready to peg its currency to a reserve currency. This announcement leads not only to a crash in the Indonesian stock market, but also to a significant decline in the Philippines and in Malaysia. The evidence points out that we should not specify the null hypothesis as no significant increase in cross-market linkages, but rather as no significant change in these linkages, a point already noted in section 3 when we discuss the methodology. Therefore, even if it is true that at times of crises capital flows out of the region, it seems that investors reallocate funds within the south-east Asian region according to country-specific news.

\begin{tabular}{|c|c|c|c|}
\hline \multicolumn{4}{|c|}{ "Table 4: Transmission of shocks } \\
\hline & & \multicolumn{2}{|c|}{ Type of shock } \\
\hline & & Positive & Negative \\
\hline \multirow{2}{*}{$\begin{array}{c}\text { Effect on other } \\
\text { markets }\end{array}$} & Positive & 0.52 & 0.25 \\
\hline & Negative & 0.48 & 0.75 \\
\hline
\end{tabular}

It is interesting to examine the direction of the transmission in more details. We find that about half of the positive shocks are transmitted positively (0.52), in the sense that a soaring stock market in one country leads another market to surge as well. By definition, half of the positive shocks are transmitted negatively (0.48), which points out to the fact that investors sell in one market and reinvest into another market, reinforcing the conclusion developed in the previous paragraph. However, three quarters of the negative shocks have negative effects, in the sense that a crash in one market leads to a crash in another market. By definition, again, one quarter of country-specific crashes leads to rising stock market in other countries. Thus, we obtain prima facie evidence of an asymmetric international transmission of countryspecific shocks. Whereas positive shocks can lead to increases or decreases in other markets with a nearly equal probability, negative shocks are more likely to lead to adverse effects on neighbouring stock markets.

Such empirical evidence could not be obtained with alternative methodologies to test for the existence of contagion. Correlation analysis relies on a comparison of correlation coefficients across periods of low and high turbulence. The limitedinformation approach of Rigobon (2000) does not require the estimation of a structural model and only computes a test statistic. Both these approaches do not identify idiosyncratic shocks explicitly and therefore, we cannot examine the direction of the impact of such shocks on other stock markets.

One final remark is noteworthy. Country-specific shocks tend to occur in clusters over time. In other words, we observe clusters of very high financial market turbulence with more tranquil periods otherwise. The financial data show clusters 
such as early July 1997, early September 1997, then a long sequence of shocks from early November to early February 1998, with more dispersed shocks for the end of the sample. Nowadays, the empirical literature on contagion focuses on the so-called 1997/98 Asian crisis. However, we should remember that this crisis was initially seen as a Thai crisis. It is only after a few months that it was clearly understood that speculative attacks and financial crises would affect the whole region, including Korea which had been recently admitted as a member of the OECD. In fact, it is interesting to see that Korea was not affected by contagious effects until early December 1997. The first bold coefficient for Korea corresponds to 8th December 1997. Once that this country was undergoing severe difficulties, however, it has suffered from contagious effects from neighbouring countries.

\subsection{Implications for international portfolio diversification}

The fundamental reason behind international portfolio diversification remains that it allows to expand the investment opportunity set. Investors are able to allocate wealth between a higher number of securities, thereby reducing the effect of idiosyncratic risk. There is empirical evidence showing that indeed, diversifying internationally brings about an economically significant gain (Solnik [1997], Griffin and Karolyi [1998] and Nilsson [2002]).

However, to the extent that stock market comovements increase at times of market distress, the gains from international portfolio diversification should be reduced just when they are most needed. Butler and Joaquin (2002) find that these gains decrease in bear markets. The strategy is to divide the sample of stock market returns into three categories, namely bear, normal and bull markets. Correlations are higher in bear markets than in normal or bull markets. Then, they build an equally weighted portfolio of the domestic market and the international market and find that its return is reduced by about $2 \%$ in bear markets compared to what it would have been if crossmarket linkages would not change. Das and Uppal (2002) study simultaneous jumps in stock market returns and interpret such jumps as contagious events leading to systemic risk. They find evidence that such systemic risk decreases the gains from international diversification only marginally.

The common feature of the studies which quantify the reduction in gains from diversification is the assumption that cross-market linkages increase during periods of high turbulence. However, as our results show, we should really focus on changes in cross-market linkages and not exclusively on increases. Positive and negative shocks affect other stock markets with different probabilities. These features of contagion should be taken into account. We have found cases where cross-market relationships actually decrease, thereby potentially increasing the gains from diversifying across markets. Assuming that markets exhibit greater comovements at times of distress is a limiting assumption. 


\section{The limits of the limited-information approach}

This section examines the reasons behind the divergence of our results relative to those obtained by Rigobon (2001, 2002) obtained with the limited-information approach. We make use of Monte Carlo simulations and show that this approach features some limitations which may lead to not rejecting the null hypothesis of no contagion when it should in fact be rejected. We proceed as follows. Firstly, we follow closely Favero and Giavazzi (2002) to show that in the context of the limited-information method a test for contagion is a Hausman test for the validity of the constructed instrument. Secondly, we lay out the setup of our Monte Carlo experiments with particular emphasis on the various assumptions that characterize the procedure. Thirdly, we present the results of some simulation experiments.

\subsection{A test for contagion as a Hausman test}

Monte Carlo simulations assume that the true data generating process is known to the researcher. This process should be specified either under some null hypothesis or some alternative hypothesis. Once that the data have been generated, we can apply estimation methods and/or statistical tests to examine the problem under investigation.

Our underlying econometric model is a bivariate dynamic system of simultaneous equations given by

$$
\left(\begin{array}{cc}
1 & -\beta_{12} \\
-\beta_{21} & 1
\end{array}\right)\left(\begin{array}{c}
s_{1, t} \\
s_{2, t}
\end{array}\right)=\left(\begin{array}{cc}
\gamma_{11} & 0 \\
0 & \gamma_{22}
\end{array}\right)\left(\begin{array}{l}
s_{1, t-1} \\
s_{2, t-1}
\end{array}\right)+\left(\begin{array}{l}
1 \\
\delta
\end{array}\right) z_{t}+\left(\begin{array}{l}
\varepsilon_{1, t} \\
\varepsilon_{2, t}
\end{array}\right)
$$

where $z_{t}$ is a common unobservable shock and $\varepsilon_{1, t}$ and $\varepsilon_{2, t}$ are idiosyncratic shocks. For the sake of the exposition, and without loss of generality, we will assume that $\gamma_{i j}=0, \forall i, j$, and that $z_{t}=0$. The system reduces to

$$
\left(\begin{array}{cc}
1 & -\beta_{12} \\
-\beta_{21} & 1
\end{array}\right)\left(\begin{array}{c}
s_{1, t} \\
s_{2, t}
\end{array}\right)=\left(\begin{array}{l}
\varepsilon_{1, t} \\
\varepsilon_{2, t}
\end{array}\right)
$$

The sample will include abnormal high-volatility events. The limited-information approach relies on splitting the whole sample conditional on the volatility regime. In other words, we will identify two different regimes according to whether volatility is high or low. In terms of the full-information approach of Favero and Giavazzi (2002), for the high-volatility regime we obtain ${ }^{22}$

$$
\left(\begin{array}{cc}
1 & -\beta_{12} \\
-\beta_{21} & 1
\end{array}\right)\left(\begin{array}{l}
s_{1, t}^{h} \\
s_{2, t}^{h}
\end{array}\right)=\left(I+\left(\begin{array}{ll}
a_{11} & a_{12} \\
a_{21} & a_{22}
\end{array}\right)\left(\begin{array}{cc}
d_{1, t} & 0 \\
0 & d_{2, t}
\end{array}\right)\right)\left(\begin{array}{l}
\varepsilon_{1, t}^{l} \\
\varepsilon_{2, t}^{l}
\end{array}\right)
$$

\footnotetext{
${ }^{22}$ For the construction of these equations, we refer the reader to section 3 of this paper.
} 
and for the low-volatility regime we have

$$
\left(\begin{array}{cc}
1 & -\beta_{12} \\
-\beta_{21} & 1
\end{array}\right)\left(\begin{array}{c}
s_{1, t}^{l} \\
s_{2, t}^{l}
\end{array}\right)=\left(\begin{array}{c}
\varepsilon_{1, t}^{l} \\
\varepsilon_{2, t}^{l}
\end{array}\right)
$$

Suppose that we are interested in estimating the coefficient $\beta_{21}$. Rigobon (2000) proposes the following instrument to implement the estimation by instrumental variables:

$$
w_{t}=\left(\begin{array}{c}
\frac{s_{1, t}^{h}}{T^{h}} \\
-\frac{s_{1, t}^{l}}{T^{l}}
\end{array}\right)
$$

Hence,

$$
\widehat{\beta}_{21}=\left(w^{\prime} s_{1}\right)^{-1} w^{\prime} s_{2}
$$

We now demonstrate that this instrument is valid only under the null hypothesis of no contagion, so that a test for the stability of parameters can be simply implemented as a Hausman test for the validity of instruments. The usual conditions for validity and consistency are

$$
\begin{aligned}
& p \lim \left(w_{t} s_{1, t}\right) \neq 0 \\
& p \lim \left(w_{t} \varepsilon_{2, t}\right)=0
\end{aligned}
$$

In words, the instrument should be correlated with the original endogenous explanatory variables, whereas it should be uncorrelated with the error term. In the context of the limited-information approach, the null hypothesis is defined as parameter stability. However, the alternative hypothesis can be interpreted either as parameter instability or as a violation of the assumption that only the variance of one of the idiosyncratic shocks increases. Therefore, in what follows we assume that only $\sigma_{\varepsilon_{1}}^{2}$ increases in the sub-sample of high volatility. So,

$$
\begin{aligned}
\operatorname{Var}\left(\varepsilon_{1} \mid C\right) & >\operatorname{Var}\left(\varepsilon_{1}\right) \\
\operatorname{Var}\left(\varepsilon_{2} \mid C\right) & =\operatorname{Var}\left(\varepsilon_{2}\right) \\
\operatorname{Var}(z \mid C) & =\operatorname{Var}(z)
\end{aligned}
$$

Looking at equation (32) our specific assumption on the variances implies that $a_{12}=a_{22}=0$. The model simplifies to ${ }^{23}$

\footnotetext{
${ }^{23}$ We would obtain the same model by setting $d_{2, t}=0$ in (32).
} 


$$
\begin{aligned}
& \left(\begin{array}{cc}
1 & -\beta_{12} \\
-\beta_{21} & 1
\end{array}\right)\left(\begin{array}{l}
s_{1, t}^{h} \\
s_{2, t}^{h}
\end{array}\right)=\left(I+\left(\begin{array}{ll}
a_{11} & 0 \\
a_{21} & 0
\end{array}\right)\left(\begin{array}{cc}
d_{1, t} & 0 \\
0 & d_{2, t}
\end{array}\right)\right)\left(\begin{array}{l}
\varepsilon_{1, t}^{l} \\
\varepsilon_{2, t}^{l}
\end{array}\right) \\
& \left(\begin{array}{cc}
1 & -\beta_{12} \\
-\beta_{21} & 1
\end{array}\right)\left(\begin{array}{l}
s_{1, t}^{l} \\
s_{2, t}^{l}
\end{array}\right)=\left(\begin{array}{l}
\varepsilon_{1, t}^{l} \\
\varepsilon_{2, t}^{l}
\end{array}\right)
\end{aligned}
$$

We are now ready to check the two conditions for validity and consistency of the instrument. Firstly,

$$
\begin{aligned}
p \lim \left(w_{t} s_{1, t}\right) & =p \lim \left(\frac{1}{T^{h}} s_{1}^{h \prime} s_{1}^{h}\right)-p \lim \left(\frac{1}{T^{l}} s_{1}^{l \prime} s_{1}^{l}\right) \\
& \simeq \operatorname{var}\left(s_{1}^{h}\right)-\operatorname{var}\left(s_{1}^{l}\right) \\
& =\left(\frac{\left(\beta_{12} a_{21}+a_{11}\right) d_{1}}{1-\beta_{12} \beta_{21}}\right)^{2} \sigma_{\varepsilon_{1}}^{2}>0
\end{aligned}
$$

provided that $\beta_{12} \beta_{21} \neq 1$. Therefore, the instrument is correlated with the original endogenous variable as long as the heteroscedasticity in country 1 increases in the high-volatility sub-sample, that is, as long as $d_{1} \neq 0$. In particular, the efficiency of the instrument will depend on the relative heteroscedasticity across sub-samples of low and high volatility. Secondly, denoting $\varepsilon_{2}^{*}=\varepsilon_{2}+a_{21} d_{1} \varepsilon_{1}$,

$$
\begin{aligned}
p \lim \left(w^{\prime} \varepsilon_{2}^{*}\right) & =p \lim \left(\frac{1}{T^{h}} s_{1}^{h \prime} \varepsilon_{2}^{*}\right)-p \lim \left(\frac{1}{T^{l}} s_{1}^{l \prime} \varepsilon_{2}^{*}\right) \\
& \simeq \operatorname{cov}\left(s_{1}^{h}, \varepsilon_{2}^{*}\right)-\operatorname{cov}\left(s_{1}^{l}, \varepsilon_{2}^{*}\right) \\
& =\frac{d_{1}^{2}}{1-\beta_{12} \beta_{21}}\left(\beta_{12} a_{21}^{2}+a_{11} a_{21}\right) \sigma_{\varepsilon_{1}}^{2}
\end{aligned}
$$

which is equal to zero only under the null hypothesis of no contagion, that is, when $a_{21}=0$. Therefore, again, a test for contagion can be simply implemented as a Hausman test for the validity of the instrument.

Clearly, these results illustrate the large-sample, or asymptotic, properties of the constructed instrument. In practice, however, only finite samples of data are available. Therefore, it remains important to study the finite-sample properties of the methodology. Such an investigation being very cumbersome analytically in the present context, we make use of Monte Carlo simulations to study the power of the limited-information technique.

\subsection{Setup of the Monte Carlo simulation}

We turn to a complete description of the setup of our simulations. We start by describing the data generating process with a detailed discussion on the way idiosyncratic shocks are obtained. The underlying econometric model is given by (30) which is reproduced below. 


$$
\left(\begin{array}{cc}
1 & -\beta_{12} \\
-\beta_{21} & 1
\end{array}\right)\left(\begin{array}{l}
s_{1, t} \\
s_{2, t}
\end{array}\right)=\left(\begin{array}{cc}
\gamma_{11} & 0 \\
0 & \gamma_{22}
\end{array}\right)\left(\begin{array}{l}
s_{1, t-1} \\
s_{2, t-1}
\end{array}\right)+\left(\begin{array}{l}
1 \\
\delta
\end{array}\right) z_{t}+\left(\begin{array}{l}
\varepsilon_{1, t} \\
\varepsilon_{2, t}
\end{array}\right)
$$

This is a structural system of simultaneous equations which is exactly identified by restricting the lag structure. When each equation is identified it is possible to associate unique structural parameter values with the reduced-form system.

Since we are interested in studying the power of the test proposed by Rigobon (2000) we will generate the values for the endogenous variables under the alternative hypothesis. In that context a rejection of the null hypothesis implies either that the parameters are not stable or that the necessary assumption that the variance of only one of the idiosyncratic shocks increases in a sub-sample of the data is not satisfied. Therefore, we will assume that only the variance of $\varepsilon_{1}$ changes in a sub-sample of the data, whereas the variances of $\varepsilon_{2}$ and $z$ are constant over the entire sample. In this way we guarantee that a rejection of the null hypothesis is really a rejection of parameter stability.

The stock market in country 1 is affected by occasional abnormal high-volatility events. Such events are drawn from a binomial distribution in which the probability of an event is varied across successive experiments. Then, we can construct two subsamples according to whether an event has taken place or not. In the low-volatility regime, where no event occurs, the standard deviation of all the shocks is identical and normalized to 0.02. In the high-volatility regime, we increase the standard deviation of $\varepsilon_{1}$ by a factor $\lambda>1$ in successive experiments, whereas the standard deviations of the other shocks remain constant. In all experiments, idiosyncratic and common unobservable shocks are drawn from a normal distribution with mean zero and variance defined as explained.

We also assign some parameter values to the structural parameters. Since we generate the observations under the alternative hypothesis of parameter instability, we select different values for the interdependence coefficients conditional on the volatility regime, either low $(L)$ or high $(H)$.

\begin{tabular}{||c|c||}
\hline \hline \multicolumn{2}{||c||}{ Table 5: Baseline parameter values } \\
\hline \hline Coefficient & Value \\
\hline$\beta_{12}^{L}$ & 0.30 \\
\hline$\beta_{12}^{H}$ & 0.40 \\
\hline$\beta_{21}^{L}$ & 0.20 \\
\hline$\beta_{21}^{H}$ & 0.40 \\
\hline$\gamma_{11}$ & 0.15 \\
\hline$\gamma_{22}$ & 0.15 \\
\hline$\delta$ & 0.80 \\
\hline \hline
\end{tabular}

Since we are dealing with a dynamic model we must also specify starting values. The focus of our analysis being stock market returns, we choose $s_{1,0}=s_{2,0}=0$. We 
use the reduced-form model to generate observations for both endogenous variables. We then construct the instruments as proposed by Rigobon (2000) and explained in the previous sub-section. Finally, we compute the test and check whether the instrument is valid or not ${ }^{24}$.

This whole analysis is replicated 100 times for each value of the probability of an event and for each value of the increase in the variance of the idiosyncratic shock in country 1 . These two values are varied across successive experiments. We conjecture that the smaller the size of the sub-sample of events, and the smaller the relative increase in $\sigma_{\varepsilon_{1}}^{2}$, the smaller the power of the test. Intuitively, asymptotic results will not apply if the size of the high-volatility sub-sample is very small. Moreover, the efficiency of the instrumental-variable estimator will increase with the relative heteroscedasticity across sub-samples of high and low volatility.

\subsection{Simulation results}

We start by studying a baseline model. Its parameters are chosen in line with the empirical evidence obtained from our estimation of the structural model of interdependence which results are given in section 5 . The sample contains $N=500$ observations. Typically, the standard deviation of shocks in normal times is about 0.02 whereas it doubles in periods of high turbulence. Moreover, across the whole sample between two and three percent of the observations for each country represent abnormal high-volatility events.

Table 6 presents our simulation results for the baseline model. The numbers inside the table are probabilities (multiplied by 100) that the estimator rejects the null hypothesis, as it should. To interpret the results, the first row of numbers in italics of the table contains values ranging from 0.02 to 0.20 . These correspond to the standard deviation of the idiosyncratic shock in country 1. As expected, as this standard deviation increases, the instrumental-variable estimator gains power in rejecting the null hypothesis. Clearly, if there is no increase in the variance of any idiosyncratic shock the test has no power. This is illustrated by the fact that probabilities in the second column of table 6 are close to zero. The first column of numbers in italics contains values ranging from 0.01 to 0.10 . These correspond to the percentage of observations which are abnormal. In other words, it is the relative size of the high-volatility sub-sample. As expected, the instrumental-variable estimator gains power as this relative size increases.

\footnotetext{
${ }^{24}$ We implement the Hausman test making use of artificial regressions. For more details, see Davidson and MacKinnon (1993), chp. 7. For an application to the nonlinear transmission of country-specific shocks between the United States and Germany, see Bonfiglioli and Favero (2002). Firstly, we regress the endogenous variable in the second equation of the system on a constant and the constructed instrument. We retrieve the estimated residuals and reestimate the second equation of the structural model, augmented with these residuals. Whenever these do not enter significantly, we cannot reject the null hypothesis of parameter stability.
} 


\begin{tabular}{|c|c|c|c|c|c|c|c|c|c|c|}
\hline \multicolumn{11}{|c|}{ Table 6: Baseline model } \\
\hline \multicolumn{11}{|c|}{$N=500, \beta_{12}^{L}=0.3, \beta_{12}^{H}=0.4, \beta_{21}^{L}=0.2, \beta_{21}^{H}=0.4$} \\
\hline & 0.02 & 0.04 & 0.06 & 0.08 & 0.10 & 0.12 & 0.14 & 0.16 & 0.18 & 0.20 \\
\hline 0.01 & 5 & 32 & 64 & 84 & 88 & 92 & 96 & 93 & 98 & 98 \\
\hline 0.02 & 4 & 54 & 79 & 95 & 98 & 100 & 100 & 100 & 100 & 100 \\
\hline 0.03 & 3 & 55 & 92 & 98 & 100 & 100 & 100 & 100 & 100 & 100 \\
\hline 0.04 & 5 & 79 & 100 & 100 & 100 & 100 & 100 & 100 & 100 & 100 \\
\hline 0.05 & 6 & 77 & 98 & 100 & 100 & 100 & 100 & 100 & 100 & 100 \\
\hline 0.06 & 4 & 89 & 99 & 100 & 100 & 100 & 100 & 100 & 100 & 100 \\
\hline 0.07 & 7 & 88 & 100 & 100 & 100 & 100 & 100 & 100 & 100 & 100 \\
\hline 0.08 & 8 & 90 & 100 & 100 & 100 & 100 & 100 & 100 & 100 & 100 \\
\hline 0.09 & 4 & 91 & 100 & 100 & 100 & 100 & 100 & 100 & 100 & 100 \\
\hline 0.10 & 11 & 92 & 100 & 100 & 100 & 100 & 100 & 100 & 100 & 100 \\
\hline
\end{tabular}

It is interesting to select the value in the table which corresponds to the parameters given by our sample of data on the Asian crisis. We found that the standard deviation of the idiosyncratic shock in a country roughly doubles in periods of high turbulence, from 0.02 to 0.04 . Moreover, we also determined that between two and three percent of all observations for each country correspond to abnormal events. This precise combination of parameters yields a value in table 6 equal to 0.55 . In words, although the model features a structural break in both equations of the dynamic system the probability that the test proposed by Rigobon (2000) rejects the null hypothesis is only about half. This value is far from the expected value of 0.95 .

On the basis of our results we conclude that the instrumental-variable estimator should be used with caution. Its power depends both on the relative size of the sub-sample of abnormal events and on the relative degree of heteroscedasticity across the two sub-samples. The evidence provided by Rigobon $(2001,2002)$ that the null hypothesis of no contagion in stock markets cannot be rejected for the 1997/98 Asian crisis could stem from the lack of power of the limited-information methodology. This evidence is a first step towards a better understanding of the divergence in the results on the existence of contagion.

We now turn to an examination of the sensitivity of the results from the baseline model to changes in key parameters. Firstly, we restrict the total number of observations to 100, while keeping other parameters constant. Table 7 presents the results. 


\begin{tabular}{|c|c|c|c|c|c|c|c|c|c|c|}
\hline$\overline{\mathrm{Tab}}$ & $\because 1$ & el & $\mathbf{n}$ & $\overline{11}$ & $\bar{b}$ & i & & & & \\
\hline$N=$ & $\overline{00, \beta_{12}^{L}}$ & $=0.3$ & $\beta_{12}^{H}=$ & $.4, \beta_{21}^{L}$ & $=0.2$ & $3_{21}^{H}=$ & & & & \\
\hline & 0.02 & 0.04 & 0.06 & 0.08 & 0.10 & 0.12 & 0.14 & 0.16 & 0.18 & 0.20 \\
\hline 0.01 & $\overline{77}$ & $\bar{~} 716$ & 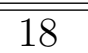 & 35 & 28 & 53 & 48 & 254 & 58 & 254 \\
\hline 0.02 & 6 & 16 & 40 & 51 & 56 & 66 & 65 & 74 & 76 & 76 \\
\hline 0.03 & 4 & 27 & 49 & 57 & 67 & 81 & 74 & 86 & 86 & 86 \\
\hline 0.04 & 5 & 25 & 59 & 74 & 76 & 84 & 90 & 91 & 94 & 96 \\
\hline 0.05 & 8 & 21 & 57 & 78 & 90 & 90 & 90 & 94 & 98 & 99 \\
\hline 0.06 & 2 & 24 & 63 & 80 & 95 & 98 & 96 & 97 & 96 & 97 \\
\hline 0.07 & 3 & 33 & 73 & 91 & 95 & 94 & 98 & 97 & 98 & 99 \\
\hline 0.08 & 5 & 32 & 76 & 89 & 91 & 97 & 99 & 99 & 100 & 100 \\
\hline 0.09 & 5 & 46 & 78 & 93 & 93 & 96 & 100 & 99 & 99 & 98 \\
\hline 0.10 & 7 & 38 & 80 & 92 & 94 & 98 & 100 & 100 & 100 & 100 \\
\hline
\end{tabular}

Clearly, the power deteriorates when the total sample size decreases. Relative to the baseline model there are less observations and asymptotic results should hold even less than under a total sample size equal to 500. In general, the larger the overall sample size, the larger the power of the test.

We also test the power of the method when the structural interdependence coefficients break in one country only. Table 8 presents the results when the baseline model is changed to $\beta_{21}^{L}=\beta_{21}^{H}=0.2$.

\begin{tabular}{|c|c|c|c|c|c|c|c|c|c|c|}
\hline \multicolumn{11}{|c|}{$\bar{c} N=500, \beta_{12}^{L}=0.3, \beta_{12}^{H}=0.4, \beta_{21}^{L}=0.2, \beta_{21}^{H}=0.2$} \\
\hline & $0.0^{\circ}$ & 0.04 & 0.06 & 0.08 & 0.10 & 0.12 & 0.14 & 0.16 & 0.18 & 0.20 \\
\hline 0.01 & 5 & 30 & 64 & 81 & 93 & 98 & 94 & 95 & 96 & 100 \\
\hline 0.02 & 3 & 53 & 89 & 98 & 99 & 99 & 99 & 100 & 99 & 100 \\
\hline 0.03 & 6 & 71 & 97 & 98 & 100 & 98 & 100 & 100 & 100 & 100 \\
\hline 0.04 & 4 & 74 & 97 & 100 & 100 & 100 & 100 & 100 & 100 & 100 \\
\hline 0.05 & 7 & 80 & 100 & 100 & 100 & 100 & 100 & 100 & 100 & 100 \\
\hline 0.06 & 3 & 82 & 100 & 100 & 100 & 100 & 100 & 100 & 100 & 100 \\
\hline 0.07 & 4 & 92 & 100 & 100 & 100 & 100 & 100 & 100 & 100 & 100 \\
\hline 0.08 & 4 & 86 & 100 & 100 & 100 & 100 & 100 & 100 & 100 & 100 \\
\hline 0.09 & 8 & 97 & 100 & 100 & 100 & 100 & 100 & 100 & 100 & 100 \\
\hline 0.10 & 8 & 97 & 100 & 100 & 100 & 100 & 100 & 100 & 100 & 100 \\
\hline
\end{tabular}

Table 9 provides the results when the baseline model is modified to $\beta_{12}^{L}=\beta_{12}^{H}=$ 0.2 . 


\begin{tabular}{|c|c|c|c|c|c|c|c|c|c|c|}
\hline$\overline{\overline{\mathrm{Tab}}}$ & $\overline{\overline{1}}$ & & $y$ in & & & & & & & \\
\hline$N=$ & $\overline{00, \beta_{12}^{L}}$ & $=0.3$ & $\beta_{12}^{H}=$ & $.3, \beta_{2}^{L}$ & $=0.2$ & $3_{21}^{H}=$ & & & & \\
\hline & 0.02 & 0.04 & 0.06 & 0.08 & 0.10 & 0.12 & 0.14 & 0.16 & 0.18 & 0.20 \\
\hline 0.01 & $\overline{55}$ & 27 & 758 & 80 & 83 & 294 & 294 & 95 & $\overline{994}$ & $\overline{96}$ \\
\hline 0.02 & 6 & 48 & 77 & 95 & 99 & 100 & 98 & 100 & 100 & 100 \\
\hline 0.03 & 6 & 54 & 91 & 98 & 99 & 100 & 100 & 100 & 100 & 100 \\
\hline 0.04 & 6 & 73 & 99 & 99 & 100 & 100 & 100 & 100 & 100 & 100 \\
\hline 0.05 & 6 & 72 & 99 & 99 & 100 & 100 & 100 & 100 & 100 & 100 \\
\hline 0.06 & 4 & 82 & 100 & 100 & 100 & 100 & 100 & 100 & 100 & 100 \\
\hline 0.07 & 8 & 90 & 100 & 100 & 100 & 100 & 100 & 100 & 100 & 100 \\
\hline 0.08 & 4 & 96 & 100 & 100 & 100 & 100 & 100 & 100 & 100 & 100 \\
\hline 0.09 & 2 & 91 & 100 & 100 & 100 & 100 & 100 & 100 & 100 & 100 \\
\hline 0.10 & 6 & 89 & 100 & 100 & 100 & 100 & 100 & 100 & 100 & 100 \\
\hline
\end{tabular}

Finally, we assume larger structural breaks in both equations. In particular, relative to the baseline model, we assume that $\beta_{12}^{H}=0.6$ and $\beta_{21}^{H}=0.6$. Table 10 summarizes the results.

\begin{tabular}{|c|c|c|c|c|c|c|c|c|c|c|}
\hline & & & & ra & & & & & & \\
\hline$N=$ & $00, \beta$ & $=0$. & $\beta_{12}^{H}=$ & $.6, \beta_{21}^{L}$ & $=0.2$ & $B_{21}^{H}=$ & & & & \\
\hline & $0.0^{\circ}$ & 0.04 & 0.06 & 0.08 & 0.10 & 0.12 & 0.14 & 0.16 & 0.18 & 0.20 \\
\hline 0.01 & $\bar{~} \overline{11}$ & 136 & 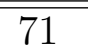 & 883 & 88 & $\overline{91}$ & $\overline{966}$ & $\overline{97}$ & $\overline{997}$ & 95 \\
\hline 0.02 & 3 & 51 & 82 & 97 & 100 & 99 & 100 & 99 & 100 & 100 \\
\hline 0.03 & 5 & 63 & 93 & 99 & 99 & 100 & 100 & 100 & 100 & 100 \\
\hline 0.04 & 4 & 68 & 99 & 100 & 100 & 100 & 100 & 100 & 100 & 100 \\
\hline 0.05 & 3 & 80 & 99 & 100 & 100 & 100 & 100 & 100 & 100 & 100 \\
\hline 0.06 & 5 & 85 & 99 & 100 & 100 & 100 & 100 & 100 & 100 & 100 \\
\hline 0.07 & 6 & 90 & 100 & 100 & 100 & 100 & 100 & 100 & 100 & 100 \\
\hline 0.08 & 1 & 89 & 100 & 100 & 100 & 100 & 100 & 100 & 100 & 100 \\
\hline 0.09 & 2 & 95 & 100 & 100 & 100 & 100 & 100 & 100 & 100 & 100 \\
\hline 0.10 & 3 & 89 & 100 & 100 & 100 & 100 & 100 & 100 & 100 & 100 \\
\hline
\end{tabular}

Overall the power of the limited-information methodology does not seem to depend largely on the number of structural breaks or on the magnitude of these breaks. However, our sensitivity analysis shows that not only the relative size of the highvolatility matters, but also the total size of the sample of data. This approach is very convenient since it does not require to impose arbitrary restrictions to obtain identification and to estimate structural models. However, it is only appropriate under certain conditions. Our Monte Carlo simulation emphasize some key parameters. 


\section{Concluding remarks}

The objective of this paper is two-fold. Firstly, we have applied the full-information methodology proposed by Favero and Giavazzi (2002) to testing for contagion during the 1997/98 Asian crisis. Our results reject the null hypothesis of no contagion, so that the transmission mechanism of country-specific shocks changes in the face of high-volatility abnormal events. In contrast with the earlier correlation approach we find that stock market comovements are either reinforced or weakened in periods of high turbulence. However, this effect features an asymmetry. While negative shocks mostly have a negative impact on other markets, positive shocks can lead to either a positive or a negative effect on these other markets, with a probability of about half. We interpret this as prima facie evidence that investors discriminate among stock markets in good times, but tend to exit all markets in bad times.

Secondly, since our results on the existence of contagion diverge with those obtained by Rigobon $(2001,2002)$ using a limited-information approach, we have presented some Monte Carlo simulations to examine the necessary conditions for the power of the latter methodology. This is especially important since this method is used in an increasing number of economic fields, e.g. monetary policy and asset prices. We find that the total size of the sample of data, the relative size of the sub-sample of abnormal events, as well as the relative degree of heteroscedasticity between sub-samples of low and high volatility, are important determinants of the power of the methodology.

Interestingly, selecting parameters on the basis of our empirical estimations leads the limited-information technology to reject the null hypothesis only with a probability of half when it should in fact be rejected with a probability of 0.95 . This result can be a first step in explaining the divergence of our results with those obtained by Rigobon (2001, 2002).

The existence of nonlinearities in the transmission of idiosyncratic shocks has important implications for portfolio management and the measurement of the potential benefits from international portfolio diversification. Firstly, changes in the transmission mechanism make it more difficult for portfolio managers to rebalance their portfolios optimally. Secondly, a usual approach to discuss the benefits of diversification relies on a consideration of cross-market correlations. It has been argued that since correlations increase during periods of crises, these benefits become reduced just when they are most needed. Our results show that such statements are incomplete since changes in market comovements in times of high turbulence are not uni-directional. Further research should assess the implications of our results for the empirical measurement of the benefits of international portfolio diversification. 


\section{References}

Baig, T. and Goldfajn, I. (1999), "Financial market contagion in the Asian crisis", IMF Staff Papers 46(2), 167-195

Baumann, C. (2000), "Financial contagion in the European crises 1992/93: a correlation approach", manuscript, Graduate Institute of International Studies

Bertero, E. and Mayer, C. (1990), "Structure and performance: global interdependence of stock markets around the crash of October 1987", European Economic Review 34, 1155-1180

Bonfiglioli, A. and Favero, C. (2002), "Explaining co-movements between stock markets: the case of US and Germany", IGIER Working Paper 165

Boyer, B., Gibson, M. and Loretan, M. (1999), "Pitfalls in tests for changes in correlations", International Finance Discussion Paper 597, Board of Governors of the Federal Reserve System, Washington

Butler, K. and Joaquin, D. (2002), "Are the gains from international portfolio diversification exaggerated? The influence of downside risk in bear markets", Journal of International Money and Finance 21, 981-1011

Calvo, G., Leiderman, L. and Reinhart, C. (1993), "Capital inflows and real exchange rate appreciation in Latin America: the role of external factors", IMF Staff Papers 40(1), 108-151

Calvo, S. and Reinhart, C. (1996), "Capital flows to Latin America: is there evidence of contagion effects?", in Calvo, G., Goldstein, M. and Hochreiter, E. (eds), Private capital flows to emerging markets, Institute for International Economics, Washington

Claessens, S., Dornbusch, R. and Park, Y. (2000), "Contagion: understanding how it spreads", The World Bank Research Observer 15(2), 177-197

Corsetti, G., Pericoli, M. and Sbracia, M. (2002), "Some contagion, some interdependence: more pitfalls in tests of financial contagion", manuscript

Corsetti, G., Pesenti, P. and Roubini, N. (1999), "What caused the Asian currency and financial crisis?", Japan and the World Economy 11(3), 305-373

Davidson, R. and MacKinnon, J. (1993), Estimation and inference in econometrics, Oxford University Press

Das, S. and Uppal, R. (2002), "Systemic risk and international portfolio choice", CEPR Working Paper 3305

Dungey, M. and Zhumabekova, D. (2001), "Testing for contagion using correlations: some words of caution", Working Paper PB01-09, Center for Pacific Basin Monetary and Economic Studies, Federal Reserve Bank of San Francisco

Favero, C. and Giavazzi, F. (2002), "Is the international propagation of financial shocks non-linear?", Journal of International Economics 57, 231-246

Forbes, K. and Rigobon, R. (2001), "Measuring contagion: conceptual and empirical issues", in Claessens, S. and Forbes, K. (eds), International Financial Contagion, Kluwer Academic Publishers, Boston 
Forbes, K. and Rigobon, R. (2002), "No contagion, only interdependence: measuring stock market co-movements", Journal of Finance 57(5), 2223-2261

Frankel, J. and Rose, A. (1996), "Currency crashes in emerging markets: an empirical treatment", Journal of International Economics 41(3-4), 351-366

Frankel, J. and Roubini, N. (2001), "The role of industrial country policies in emerging market crises", forthcoming in Feldstein, M. (ed), Economic and Financial Crises in Emerging Market Economies, University of Chicago Press

Griffin, J. and Karolyi, A. (1998), "Another look at the role of the industrial structure of markets for international diversification strategies", Journal of Financial Economics 50, 352-373

Hamilton, J. (1994), Time Series Analysis, Princeton University Press

Frankel, J., Schmukler, S. and Serven, L. (2002), "Global transmission of interest rates: monetary independence and currency regime", NBER Working Paper 8828

Gindraux, Y. (2002), "Contagion of financial crises: empirical evidence from Russia and Brazil", manuscript, Graduate Institute of International Studies

King, M. and Wadhwani, S. (1990), "Transmission of volatility between stock markets", The Review of Financial Studies 3(1), 5-33

Loretan, M. and English, W. (2000), "Evaluating correlation breakdowns during periods of market volatility", International Finance Discussion Paper 658, Board of Governors of the Federal Reserve System, Washington

Milesi-Ferretti, G. and Razin, A. (1998), "Current account reversals and currency crises: empirical regularities", NBER Working Paper 6620

Moreno, R. and Trehan, B. (2000), "Common shocks and currency crises", Working Paper in Applied Economic Theory 05, Federal Reserve Bank of San Francisco

Nilsson, B. (2002), "International asset pricing and the benefits from world market diversification", manuscript, University of Lund

Pritsker, M. (2001), "The channels for financial contagion", in Claessens, S. and Forbes, K. (eds), International Financial Contagion, Kluwer Academic Publishers, Boston

Reinhart, C. and Reinhart, V. (2001), "What hurts most? G-3 exchange rate or interest volatility", manuscript

Rigobon, R. (2000), "A simple test for stability of linear models under heteroscedasticity, omitted variable, and endogenous variable problems", manuscript, MIT

Rigobon, R. (2001), "Contagion: how to measure it?", NBER Working Paper 8118

Rigobon, R. (2002), "On the measurement of the international propagation of shocks: is the transmission stable?", forthcoming in Journal of International Economics, manuscript, MIT

Sims, C. (1980), "Macroeconomics and reality", Econometrica 48, 1-48

Solnik, B. (1997), "Going global with equities", Financial Analyst Journal 53, 95-96 


\begin{tabular}{|c|c|c|c|}
\hline Date & Country & Type & News in Bloomberg \\
\hline $07 / 10 / 96$ & Thailand & - & $\begin{array}{l}\text { Bank of Thailand imposes new measures on offshore lending by foreign- } \\
\text { owned banks in an effort to better control the flow of foreign funds. Stock } \\
\text { market index plunges amid concern that high annual economic growth is a } \\
\text { thing of the past. Investors sell bahts and switch to a rising yen. }\end{array}$ \\
\hline $18 / 11 / 96$ & Thailand & - & $\begin{array}{l}\text { Phone issues fall on expectations that new projects and revised contracts will } \\
\text { not materialize soon. }\end{array}$ \\
\hline $02 / 07 / 97$ & Thailand & + & $\begin{array}{l}\text { Devaluation of the baht, in order to boost exports, scrapping a formula used } \\
\text { since } 1984 \text { that pegged the baht to a basket of foreign currencies but } \\
\text { dominated by the U.S. dollar. }\end{array}$ \\
\hline 03/07/97 & Thailand & + & $\begin{array}{l}\text { Thai stocks extend their biggest rally since } 1992 \text { on optimism a devaluation } \\
\text { will help revive its flagging economy. }\end{array}$ \\
\hline $11 / 07 / 97$ & Philippines & + & $\begin{array}{l}\text { Devaluation of the currency. Stocks soar after the central bank allows the peso } \\
\text { to weaken, giving up a costly defense strategy that drove interest rates up and } \\
\text { threatened to slow down growth significantly. }\end{array}$ \\
\hline $28 / 08 / 97$ & $\begin{array}{l}\text { Philippines, } \\
\text { Malaysia }\end{array}$ & - & $\begin{array}{l}\text { Philippine stock market crashes in the midst of panic. } \\
\text { Malaysian stocks tumble to four-year low after the stock exchange curbs } \\
\text { trading in the } 100 \text { stocks of the benchmark index. Prime Minister Mahathir } \\
\text { Mohamad asks local state-run pension funds to buy stocks the next day, and } \\
\text { blames George Soros. }\end{array}$ \\
\hline $02 / 09 / 97$ & Thailand & + & $\begin{array}{l}\text { Stocks rally, reversing a rout that slashed more than } 20 \text { percent off the } \\
\text { benchmark index in } 13 \text { days after banks reveal that bad debts are no worse } \\
\text { than investors expected. }\end{array}$ \\
\hline $03 / 09 / 97$ & $\begin{array}{l}\text { Malaysia, } \\
\text { Indonesia }\end{array}$ &,-+ & $\begin{array}{l}\text { Malaysian stock index plunges led by an electric utility, a weakening of the } \\
\text { currency, and the failure of the government's efforts to prop up the market for } \\
\text { a third day. } \\
\text { Indonesia announces "credible proactive measures" to restore stability to its } \\
\text { currency and economy. }\end{array}$ \\
\hline $05 / 09 / 97$ & $\begin{array}{l}\text { Malaysia, } \\
\text { Indonesia }\end{array}$ & + & $\begin{array}{l}\text { Malaysian Prime Minister Mahathir Mohamad says the government will raise } \\
30 \text { billion ringgit through a bond sale and use the money to buy Malaysian } \\
\text { stocks in a bid to prop up the declining stock market. } \\
\text { Indonesian stock index surges - its biggest one-day gain in almost four years } \\
\text { - after the government announces plans to boost exports and says that it will } \\
\text { abolish the 49-percent limit on foreign ownership of shares in initial public } \\
\text { offerings. }\end{array}$ \\
\hline $23 / 10 / 97$ & Philippines & - & $\begin{array}{l}\text { Bankers and brokers say that a bill pending in Congress would set back the } \\
\text { development of the Philippine capital markets by taxing stocks and bonds } \\
\text { more heavily than in other countries. }\end{array}$ \\
\hline $29 / 10 / 97$ & Indonesia & + & $\begin{array}{l}\text { Stocks jump led by domestic phone monopoly PT Telkom and tobacco } \\
\text { company Gudang Garam. }\end{array}$ \\
\hline 03/11/97 & $\begin{array}{l}\text { Korea, } \\
\text { Malaysia }\end{array}$ & + & $\begin{array}{l}\text { Korean stocks rise, recovering from early declines, as the raised ceiling on } \\
\text { foreign ownership of shares takes effect. } \\
\text { Malaysian stock index increases, its largest one-day percentage gain in two } \\
\text { months, as investors buy stocks they see as attractive relative to potential } \\
\text { earnings. }\end{array}$ \\
\hline $18 / 11 / 97$ & Malaysia & - & $\begin{array}{l}\text { Stock index plunges after the speedy approval of United Engineers' purchase } \\
\text { of share in its parent company raises concern about a lax regulatory } \\
\text { environment. }\end{array}$ \\
\hline $20 / 11 / 97$ & Malaysia & - & $\begin{array}{l}\text { Stock index plunges as investors flee some of the country's largest stocks after } \\
\text { Renong's bailout by a cash-rich unit raises concern about corporate } \\
\text { transparency. }\end{array}$ \\
\hline $24 / 11 / 97$ & Korea & - & $\begin{array}{l}\text { Stock index suffers its worst plunge in history as the country prepares to } \\
\text { forfeit years of economic growth for a bailout from the IMF, imposing tax } \\
\text { raises and spending cuts. }\end{array}$ \\
\hline $04 / 12 / 97$ & Korea & + & $\begin{array}{l}\text { Stocks surge for the biggest rally ever after the country's agreement to accept } \\
\text { a } \$ 55 \text { billion international bailout. The government promises to increase } \\
\text { access to financial markets in return for the IMF bailout. }\end{array}$ \\
\hline $08 / 12 / 97$ & Malaysia & + & $\begin{array}{l}\text { Stock index posts record gains after the government takes action to avoid } \\
\text { asking the IMF for help. }\end{array}$ \\
\hline $09 / 12 / 97$ & Malaysia & - & Stock index sinks amid concern that the government's measures to slow \\
\hline
\end{tabular}




\begin{tabular}{|c|c|c|c|}
\hline & & & economic growth will hurt corporate profits. \\
\hline $15 / 12 / 97$ & Korea & + & $\begin{array}{l}\text { The country steps back from the financial brink as the prospect of billions of } \\
\text { dollars in emergency credit from the IMF restores confidence. The Finance } \\
\text { Ministry announces that it will remove its } 10 \text {-percent daily fluctuation limit on } \\
\text { trading of the won from the next day onwards. }\end{array}$ \\
\hline $23 / 12 / 97$ & Korea & - & $\begin{array}{l}\text { International credit rating agencies downgrade Korea's foreign-currency } \\
\text { denominated debt. }\end{array}$ \\
\hline $26 / 12 / 97$ & Korea & + & $\begin{array}{l}\text { Financial markets rally after the IMF and G- } 7 \text { nations pledge } \$ 10 \text { billion in } \\
\text { accelerated aid to the country. The Bank of England asks British banks to } \\
\text { extend the length of their loans to Korean banks to ease Korea's financial } \\
\text { crisis. Korea says that it will let its banks dismiss a large number of } \\
\text { employees, removing a key obstacle to acquisitions by foreign rivals. }\end{array}$ \\
\hline 08/01/98 & Indonesia & - & $\begin{array}{l}\text { Financial crisis deepens as concerns that the IMF will suspend its \$23 billion } \\
\text { bailout package sends the stock market to a four-year low. }\end{array}$ \\
\hline 09/01/98 & Philippines & - & $\begin{array}{l}\text { Stocks plunge on fears that the economy is headed for a recession brought on } \\
\text { by rising interest rates and a plummeting currency. }\end{array}$ \\
\hline $12 / 01 / 98$ & Korea & + & $\begin{array}{l}\text { Stocks rise on optimism that the country is emerging from its financial crisis. } \\
\text { An official tells the Japanese Finance Minister Mitsuzuka that Korea's } \\
\text { economic situation is improving because of the smooth rollover of its foreign } \\
\text { debt. }\end{array}$ \\
\hline $13 / 01 / 98$ & Indonesia & + & $\begin{array}{l}\text { The government announces that it will reduce the cost of foreign investment } \\
\text { to boost confidence. The currency strengthens after the IMF says it would } \\
\text { drop a demand that Indonesia run a budget surplus in the next fiscal year. } \\
\text { Stocks rally as investors bet talks among President Suharto, the United States, } \\
\text { and the IMF will yield new reforms to put the derailed economy back on } \\
\text { track. The government announces that it will postpone } 15 \text { power and highway } \\
\text { projects to demonstrate commitment to reforms. }\end{array}$ \\
\hline 15/01/98 & Indonesia & - & $\begin{array}{l}\text { Promises of economic reforms are met with increasing scepticism. The latest } \\
\text { package of reforms arrives with a thud as the stock market falls. }\end{array}$ \\
\hline 16/01/98 & Thailand & + & $\begin{array}{l}\text { Stocks rally, posting their second-biggest gain in two months, after the IMF } \\
\text { indicates it could ease some terms of its } \$ 17.2 \text { billion bailout. }\end{array}$ \\
\hline 19/01/98 & $\begin{array}{l}\text { Philippines, } \\
\text { Korea, } \\
\text { Malaysia, } \\
\text { Thailand }\end{array}$ & + & $\begin{array}{l}\text { Philippine stocks rally as the peso rises to a two-week high, prompting } \\
\text { optimism that the country would be the first to emerge from the Asian crisis. } \\
\text { Seven UK banks decide to roll over loans to Korean banks until March } 31^{\text {st }} \text { in } \\
\text { a bid to ease Korea's economic crisis. } \\
\text { Malaysian stock index soars as investors cheer remarks by the IMF on the } \\
\text { previous Friday that the country does not need a bailout. } \\
\text { Thai stock surge amid confidence that the country will be able to loosen the } \\
\text { terms of the } \$ 17.2 \text { billion international bailout for its troubled economy. }\end{array}$ \\
\hline $30 / 01 / 98$ & \begin{tabular}{|l} 
Philippines, \\
Korea, \\
Thailand
\end{tabular} & + & $\begin{array}{l}\text { Philippine stocks soar as the trade gap narrows by } 36 \% \text {, the second smallest } \\
\text { deficit in the past three years. } \\
\text { Korean stocks rally after international lenders agree to extend } \$ 24 \text { billion of } \\
\text { commercial bank debt for as long as three years. The new Korean government } \\
\text { will support shareholder rights and force companies to provide more } \\
\text { information to investors. } \\
\text { Thai stocks surge as foreign exchange controls are lifted in a sign of } \\
\text { confidence that the baht is starting to stabilize. }\end{array}$ \\
\hline $02 / 02 / 98$ & $\begin{array}{l}\text { Philippines, } \\
\text { Thailand, } \\
\text { Indonesia }\end{array}$ & + & $\begin{array}{l}\text { Philippine stocks surge on hopes of economic recovery. } \\
\text { Thai stocks rally for a fourth day amid optimism that the country has begun to } \\
\text { turn around, helped by a lower than expected inflation in January. } \\
\text { Indonesian stock index surges, its biggest one-day rise in more than eight } \\
\text { years, on hopes that banking reforms unveiled by the government will help } \\
\text { put the economy back on track. Indonesia will end monopolies and price } \\
\text { controls for a host of basic food commodities in the next two years to meet its } \\
\text { promises to the IMF. }\end{array}$ \\
\hline $03 / 02 / 98$ & \begin{tabular}{|l} 
Philippines, \\
Malaysia, \\
Indonesia
\end{tabular} &,,-+- & $\begin{array}{l}\text { President Ramos accepts the resignation of Commissioner Kintanar of the } \\
\text { National Telecommunications Commission (NTC), who is running for } \\
\text { Congress in elections in May } 1998 \text {. } \\
\text { Malaysian stock index in its biggest one-day percentage gain ever, amid } \\
\text { optimism that Asia's currency and stock market turmoil may be near an end. }\end{array}$ \\
\hline
\end{tabular}




\begin{tabular}{|c|c|c|c|}
\hline & & & $\begin{array}{l}\text { Indonesian stocks fall as optimism fuelled by previous week's banking } \\
\text { reforms is deflated by a weakening rupiah. }\end{array}$ \\
\hline $04 / 02 / 98$ & Thailand & - & $\begin{array}{l}\text { Stock index posts its biggest one-day loss in more than seven years as } \\
\text { investors conclude that prices have gone too high given bleak company } \\
\text { earnings prospects. }\end{array}$ \\
\hline $05 / 02 / 98$ & $\begin{array}{l}\text { Malaysia, } \\
\text { Thailand }\end{array}$ & + & $\begin{array}{l}\text { Malaysia's Commerce Asset says it is in talks to merge its bank unit with } \\
\text { RHB. } \\
\text { Thai stocks rebound after their biggest tumble since } 1990 \text { after investors bet } \\
\text { the worst of the crisis is over and the baht may strengthen. }\end{array}$ \\
\hline $11 / 02 / 98$ & $\begin{array}{l}\text { Philippines, } \\
\text { Indonesia }\end{array}$ &,+- & $\begin{array}{l}\text { Philippine stocks surge as a strengthening peso bolsters investors' confidence } \\
\text { that the crisis is over. } \\
\text { Indonesian stock index posts its biggest one-day decline in five weeks on } \\
\text { investor concern that capital controls will accompany plans to peg the rupiah } \\
\text { to another currency. }\end{array}$ \\
\hline $12 / 02 / 98$ & Indonesia & - & $\begin{array}{l}\text { Stanley Fischer, deputy managing director of the IMF, says that Indonesia is } \\
\text { not ready to peg its currency to a reserve currency. A former IMF economist } \\
\text { who briefed Indonesian officials on ways to peg the rupiah to the U.S. dollar } \\
\text { says he is afraid President Suharto is now rushing headlong into a bad } \\
\text { decision to adopt the plan. }\end{array}$ \\
\hline $10 / 03 / 98$ & Malaysia & + & $\begin{array}{l}\text { Stocks rise after the government says that it is prepared to let troubled banks } \\
\text { fail, thereby easing investor concerns that cash-rich companies will be coerced } \\
\text { into buying cash-strapped companies. }\end{array}$ \\
\hline $26 / 03 / 98$ & Indonesia & + & $\begin{array}{l}\text { Stocks surge as the more stable rupiah and optimism about solutions to the } \\
\text { country's foreign debt attracts investors. }\end{array}$ \\
\hline $04 / 05 / 98$ & Korea & - & $\begin{array}{l}\text { Stocks take their biggest tumble in three weeks as violent confrontations } \\
\text { between organised labour and riot police shake the government's efforts to } \\
\text { stabilize the recession-torn economy. }\end{array}$ \\
\hline $13 / 05 / 98$ & Indonesia & - & Student protests calling for Suharto's ouster escalate in Jakarta. \\
\hline $19 / 05 / 98$ & Indonesia & + & $\begin{array}{l}\text { President Suharto promises to quickly move the country toward new elections } \\
\text { in which he will not run. }\end{array}$ \\
\hline $12 / 06 / 98$ & Korea & - & $\begin{array}{l}\text { Stock index plunges to its lowest level in more than eleven years as the } \\
\text { weakening yen challenges Korean exports. }\end{array}$ \\
\hline $17 / 06 / 98$ & Korea & + & $\begin{array}{l}\text { Banks will recommend the immediate liquidation of about } 50 \text { companies - } \\
\text { more than twice what they first proposed - in a key test of the country's } \\
\text { resolve to reshape its sprawling conglomerates. }\end{array}$ \\
\hline $19 / 06 / 98$ & Philippines & - & Stock index takes its biggest plunge in more than five months. \\
\hline $20 / 07 / 98$ & Korea & + & $\begin{array}{l}\text { Shares take their biggest rally in a month amid optimism that the combination } \\
\text { of a strong won and falling interest rates will bolster corporate profits. }\end{array}$ \\
\hline
\end{tabular}

